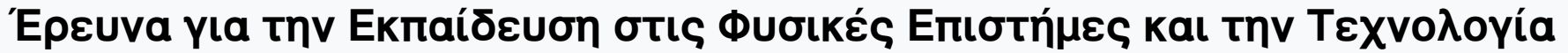

Tóp. 1, Ap. 1 (2021)

\section{Eıઠıเкó TعúXoc}

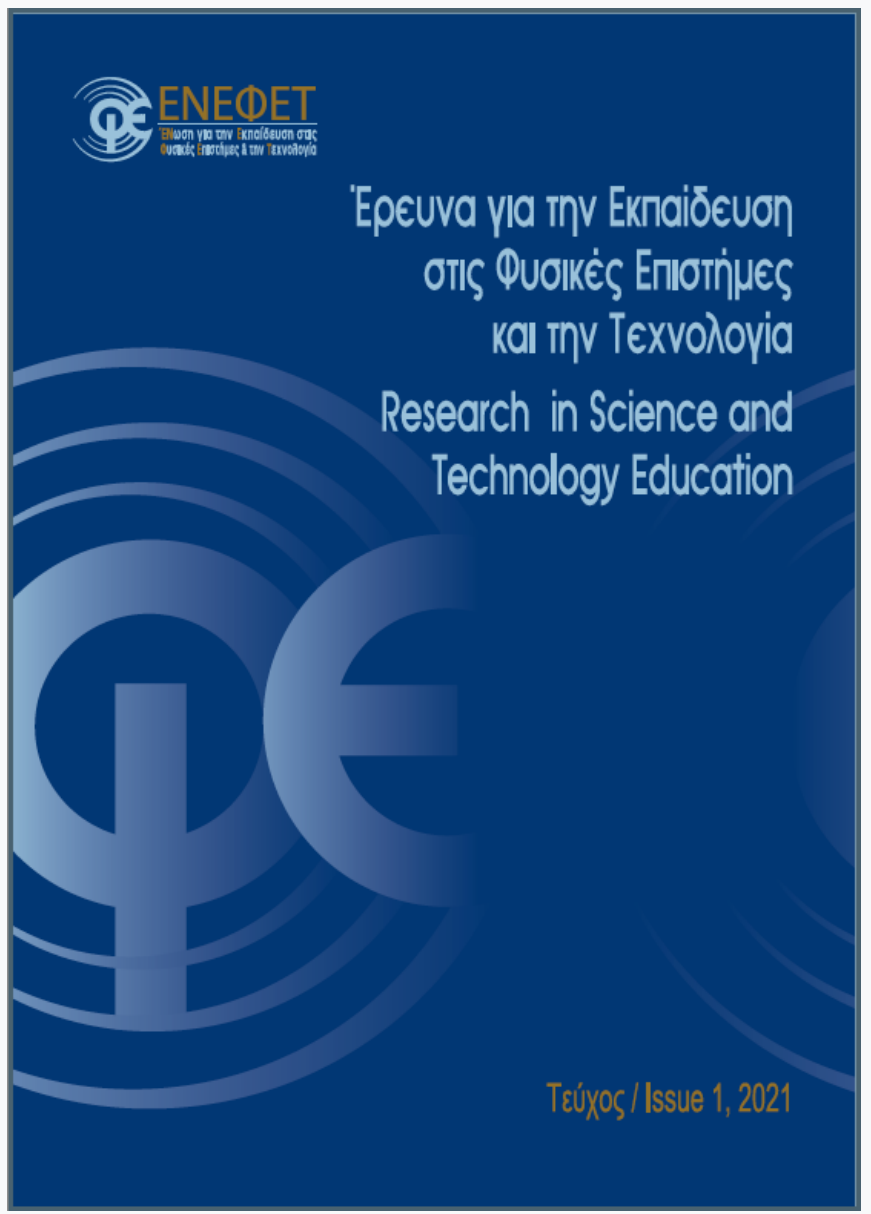

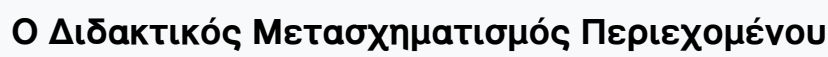

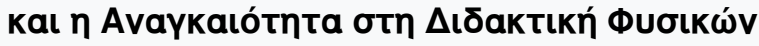

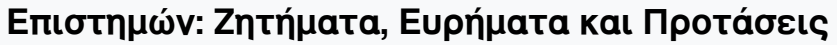

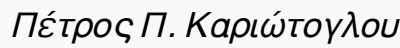

doi: $10.12681 /$ riste.27268

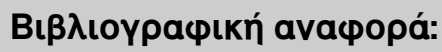

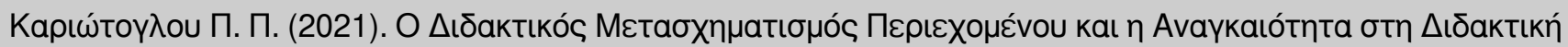

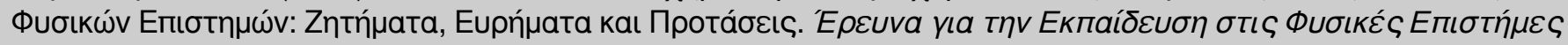

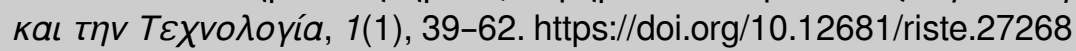




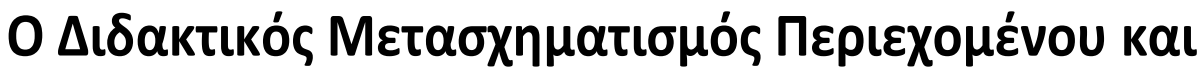

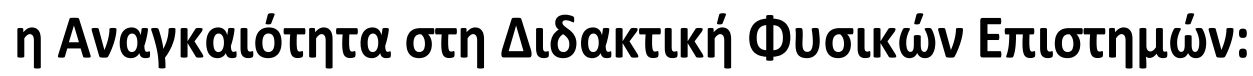

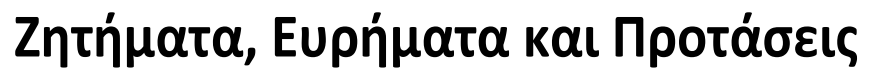

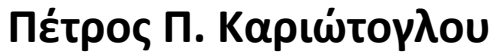

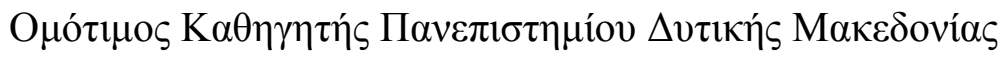 \\ pkariotog@uowm.gr
}

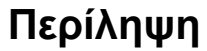

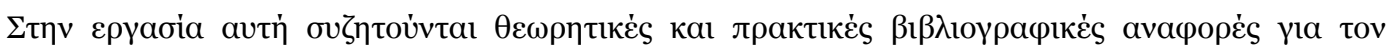

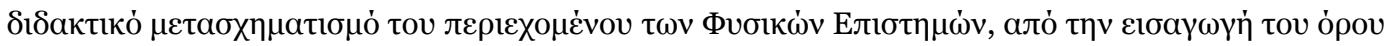

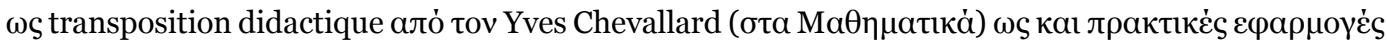

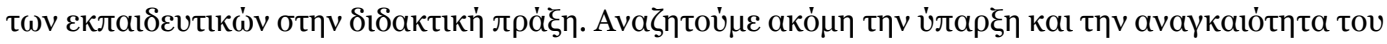

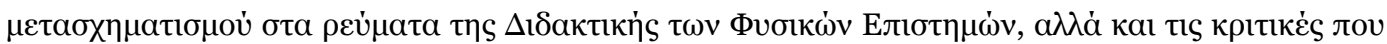

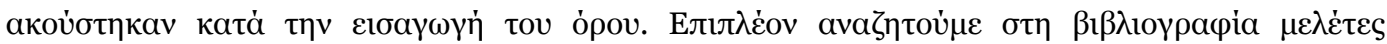

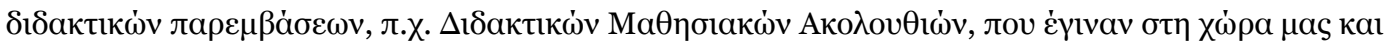

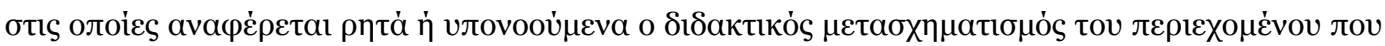

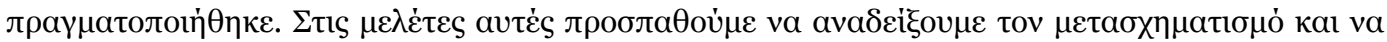

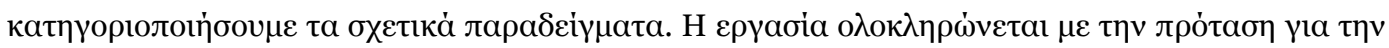

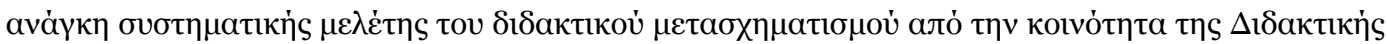

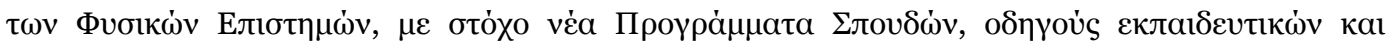

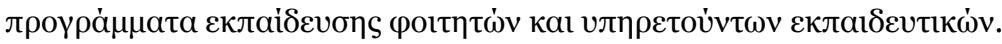

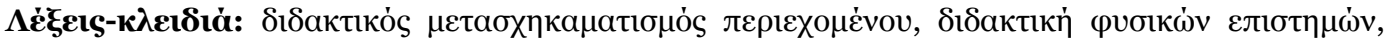

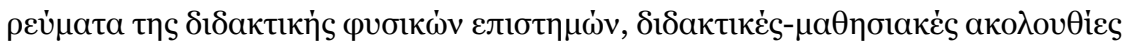

\section{Eıoaywyń}

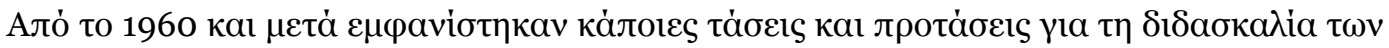

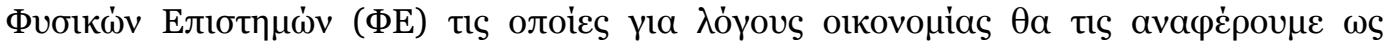

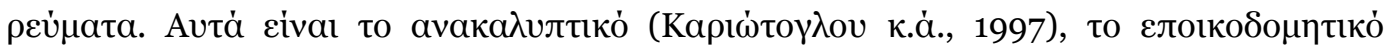




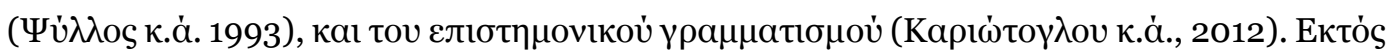

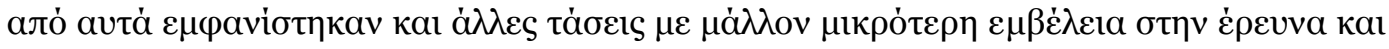

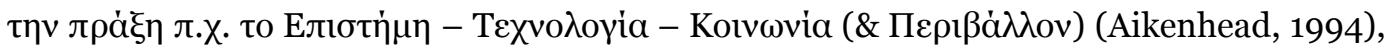

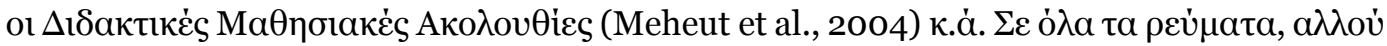

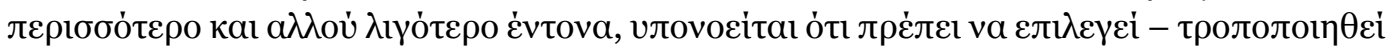

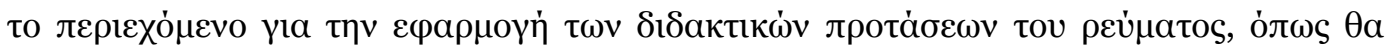

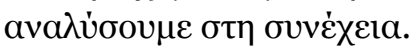

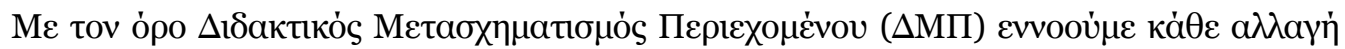

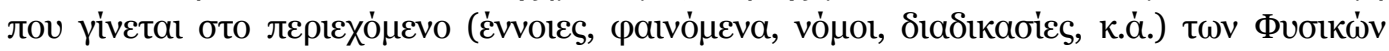

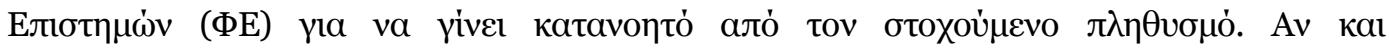

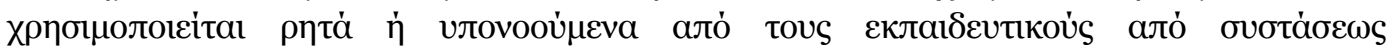

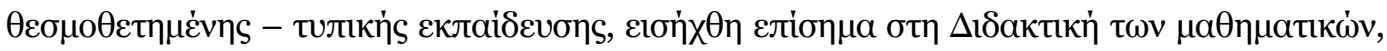

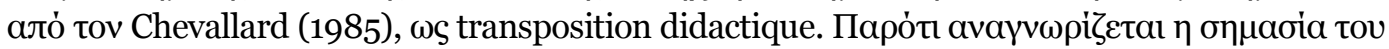

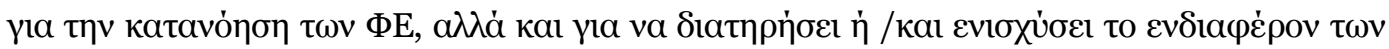

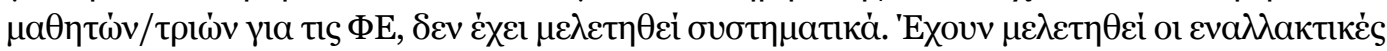

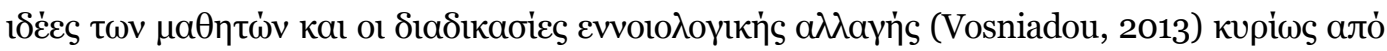

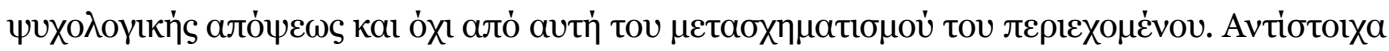

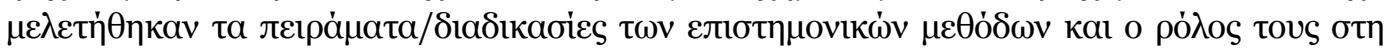

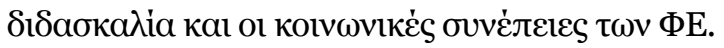

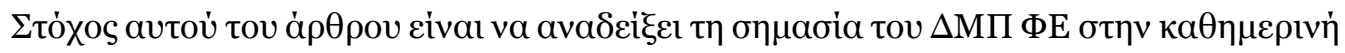

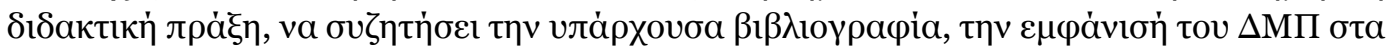

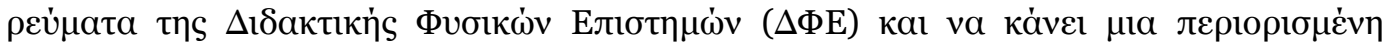

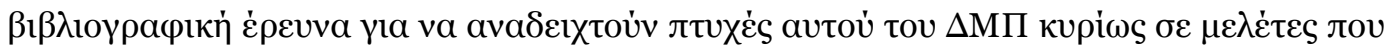

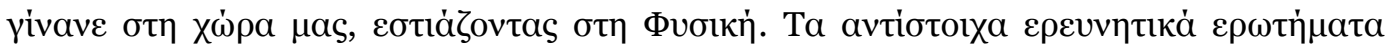
$\mu \pi о \rho \varepsilon i$ va eival:

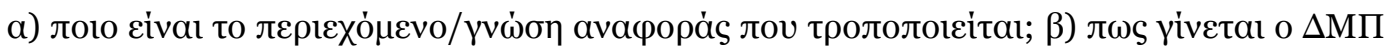

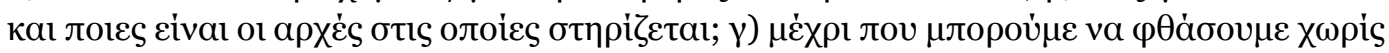

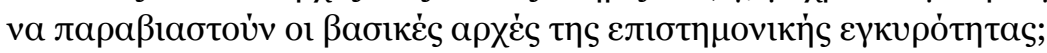

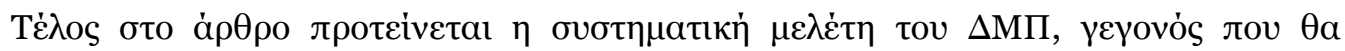

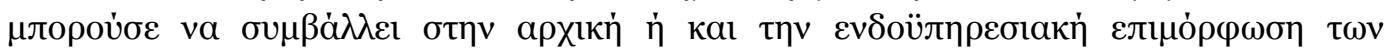

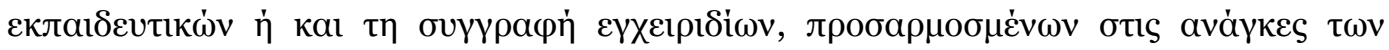
$\mu \alpha \theta \eta \tau \dot{v}$ / $\tau \rho \iota \dot{v}$ (Kariotoglou et al. 2020, Kariotoglou et al. 2019).

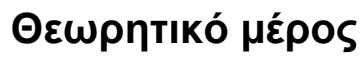

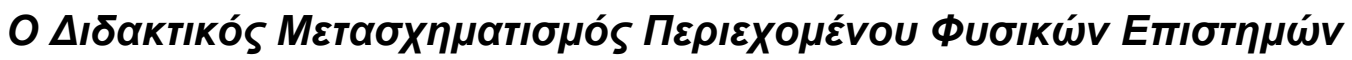

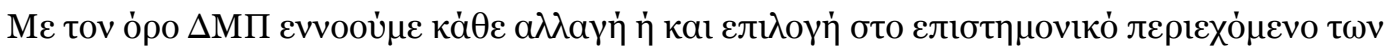

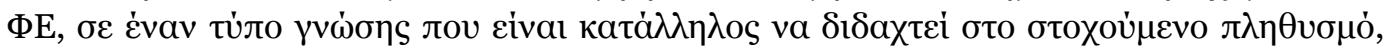

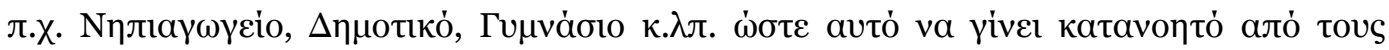

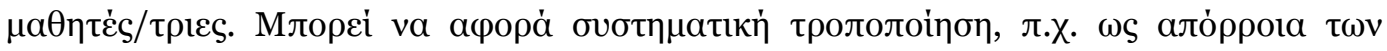




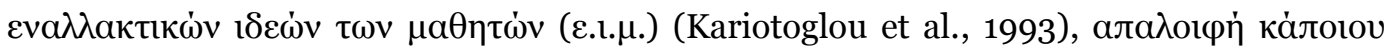

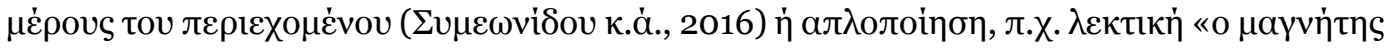

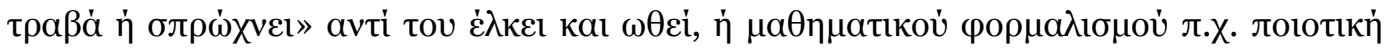

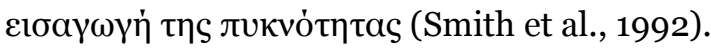

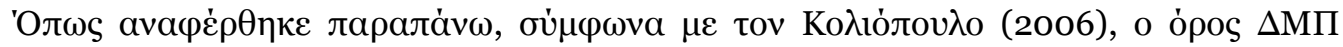

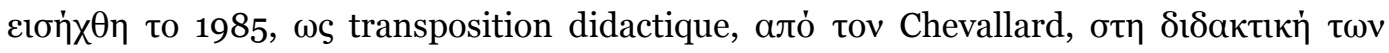

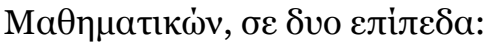

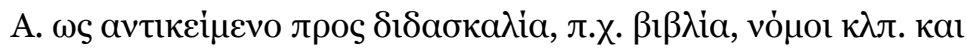

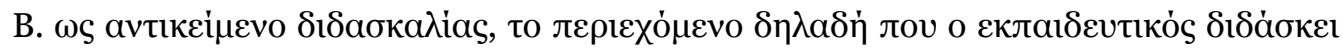

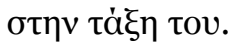

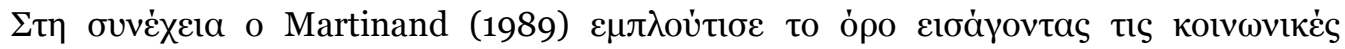

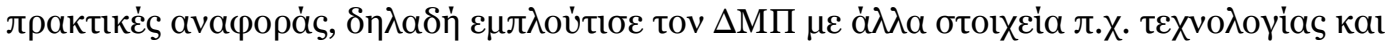

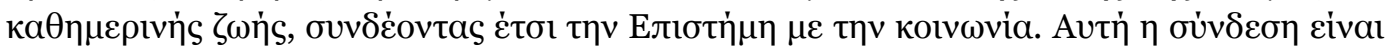

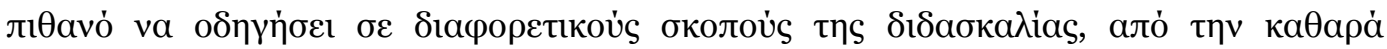

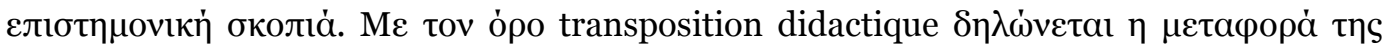

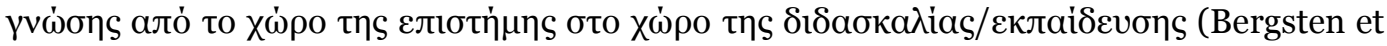

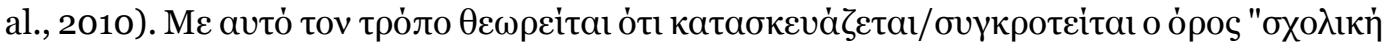

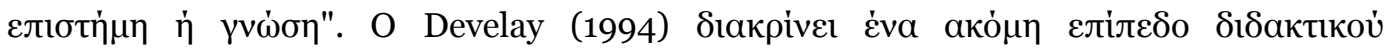

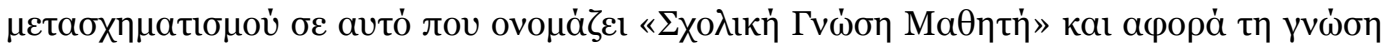

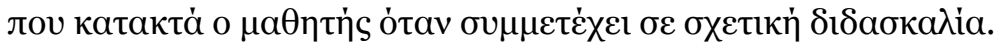

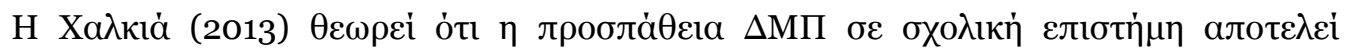

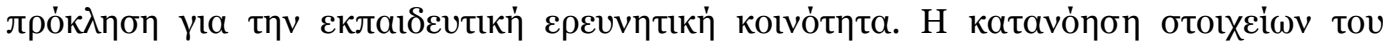

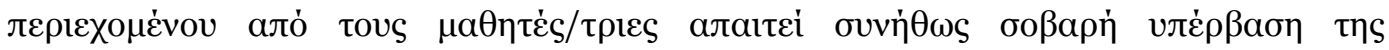

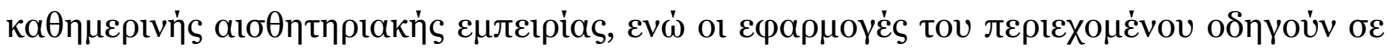

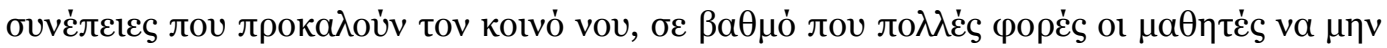

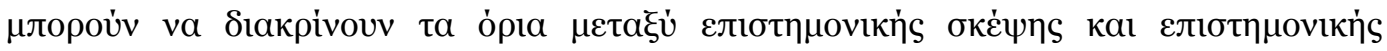
pavtaoias.

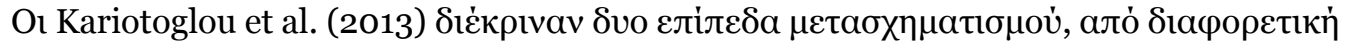

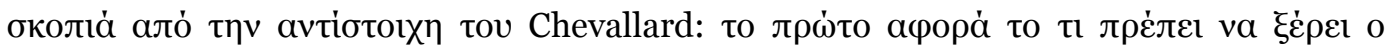

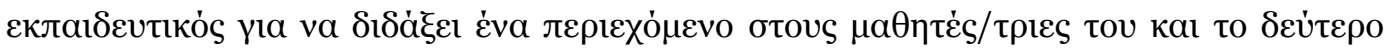

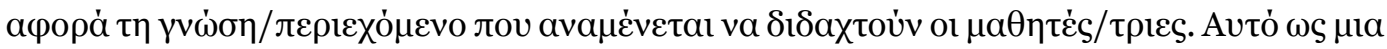

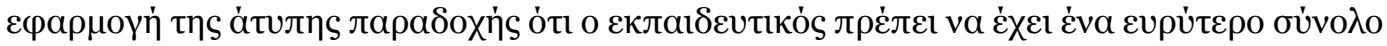

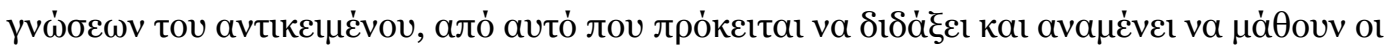
$\mu \alpha \theta \eta \tau \dot{\varepsilon} \varsigma / \tau \rho l \varepsilon \varsigma$ тov.

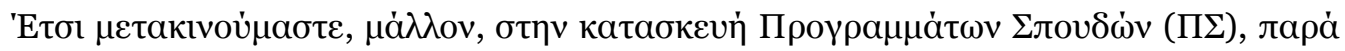

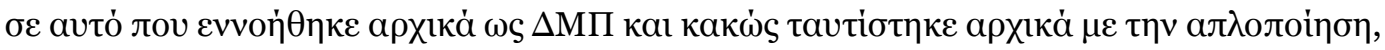

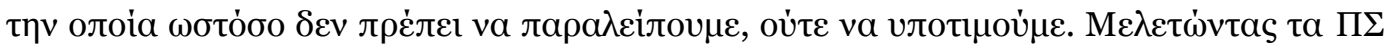

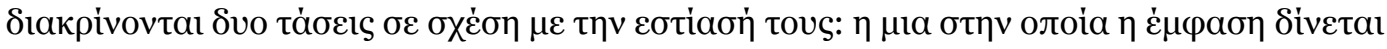

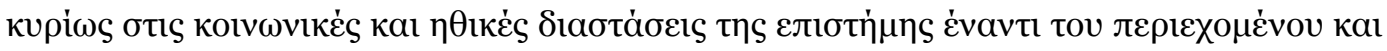




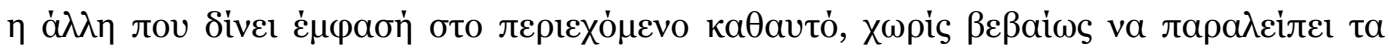

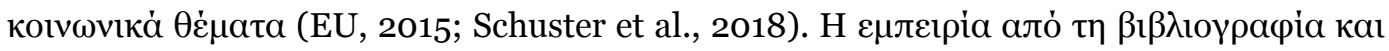

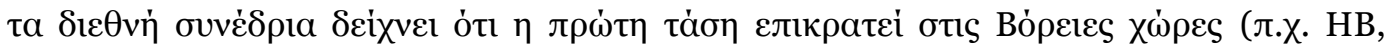

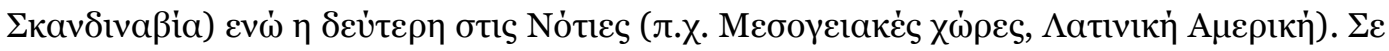

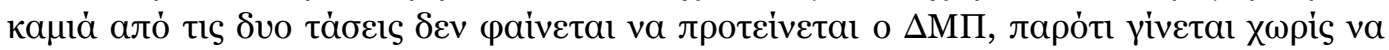

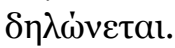

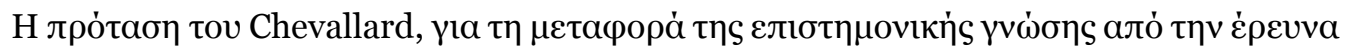

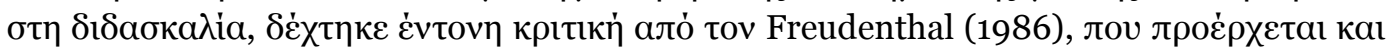

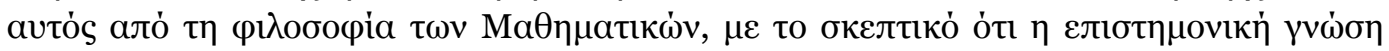

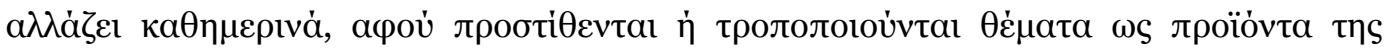

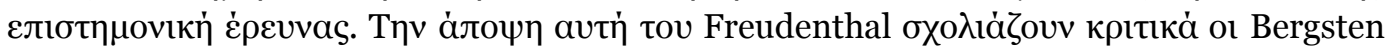

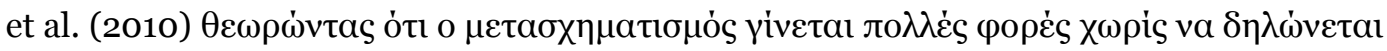

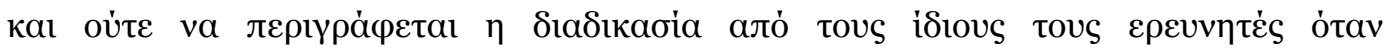

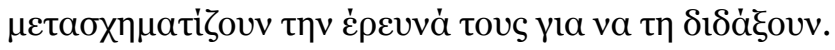

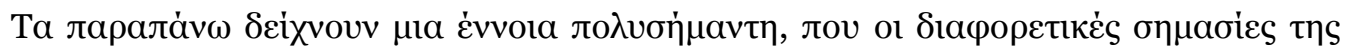

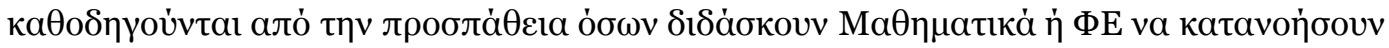

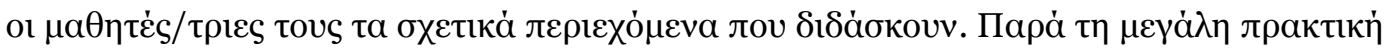

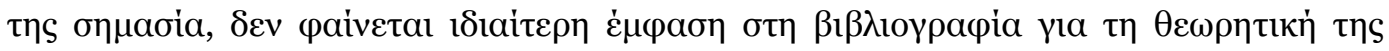

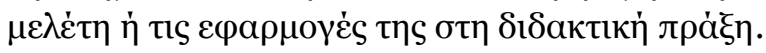

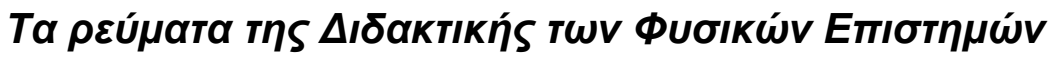

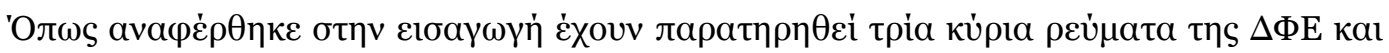

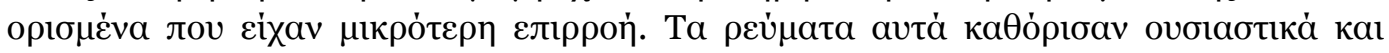

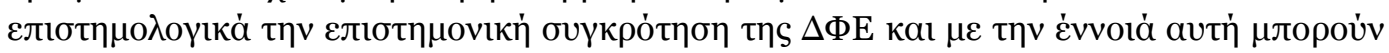

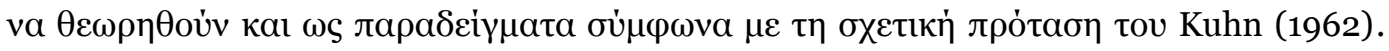

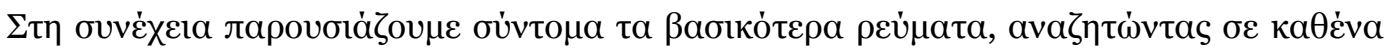

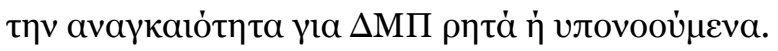

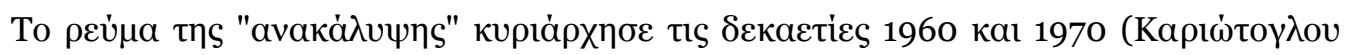

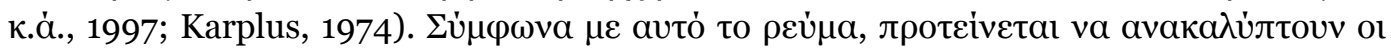

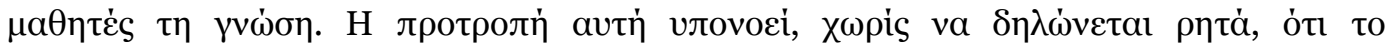

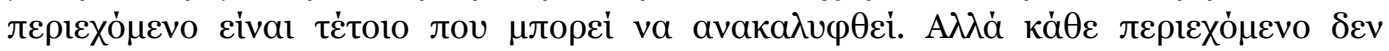

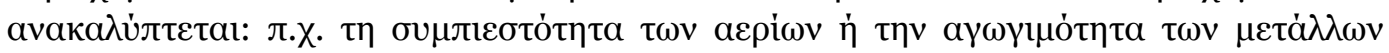

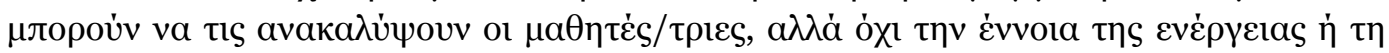

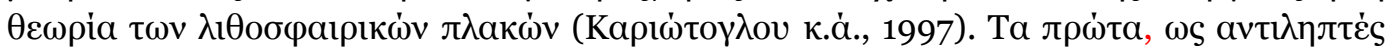

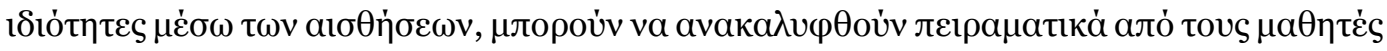

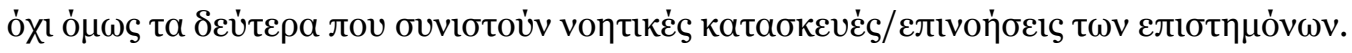

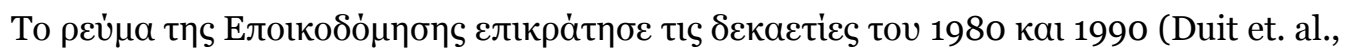

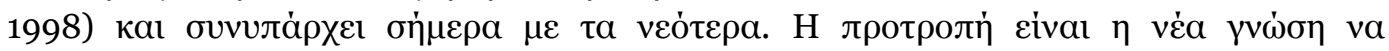

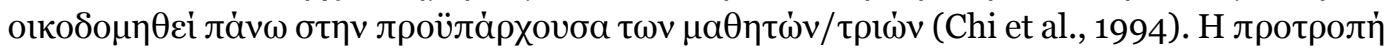




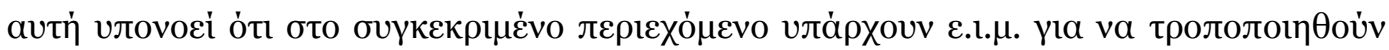

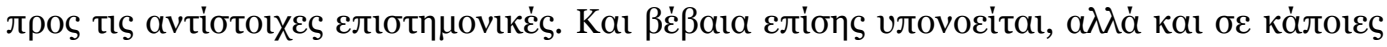

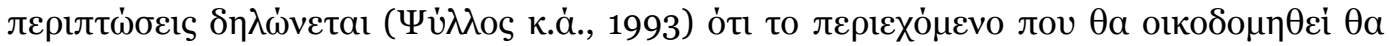

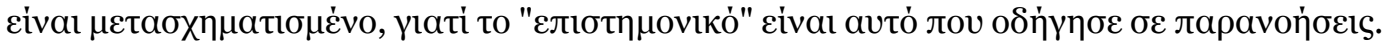

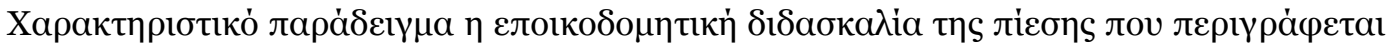

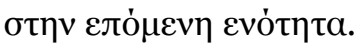

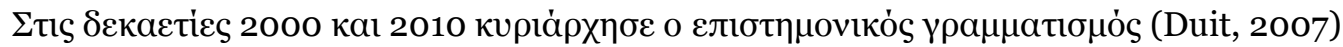

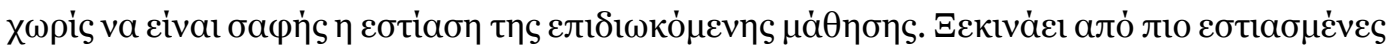

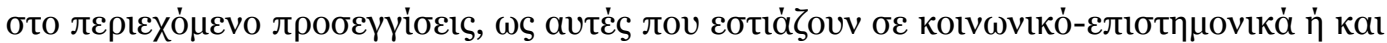

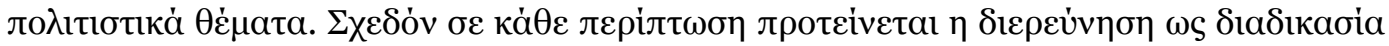

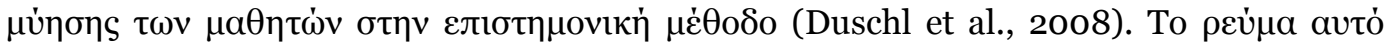

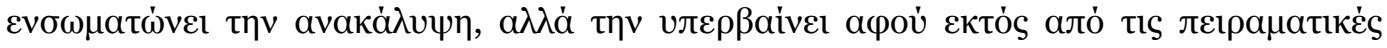

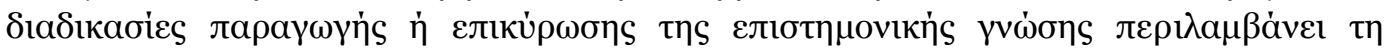

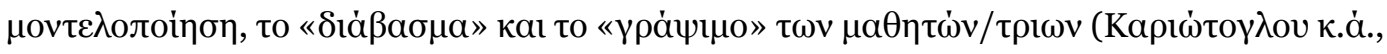

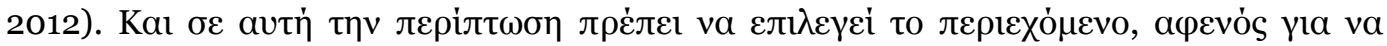

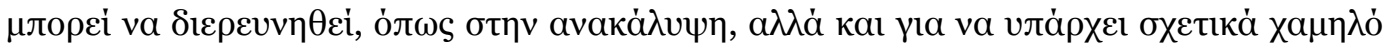

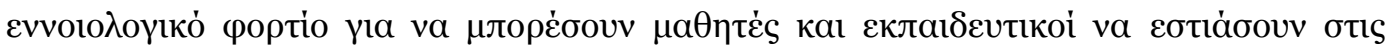

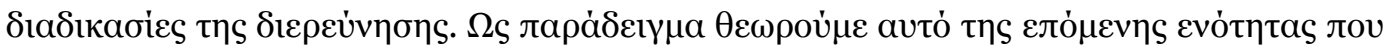

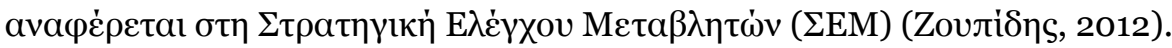

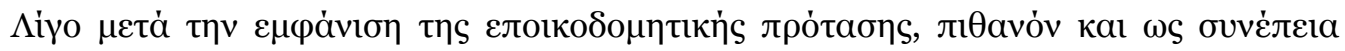

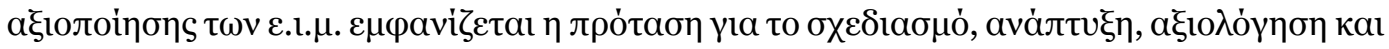

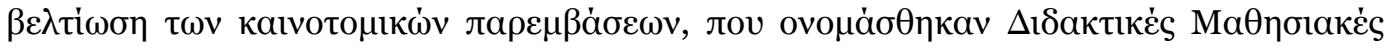

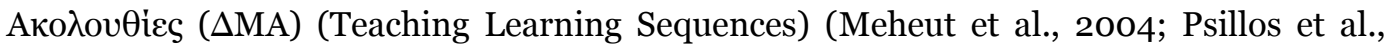

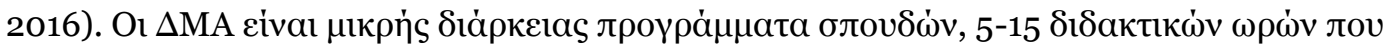

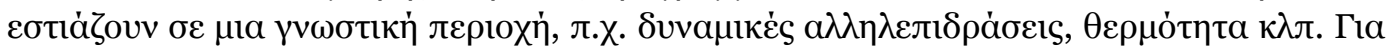

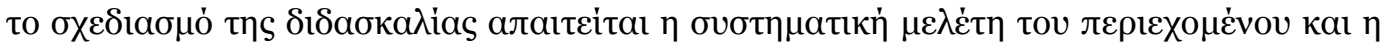

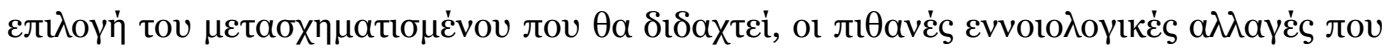

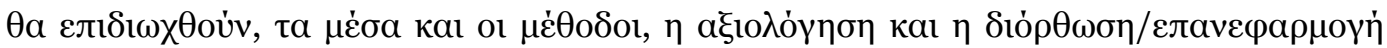

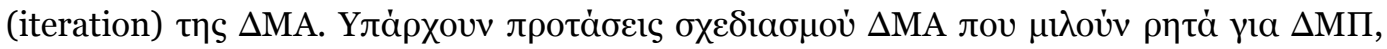

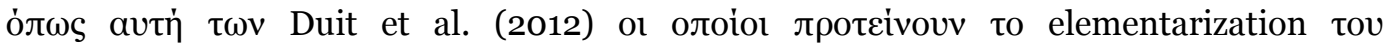

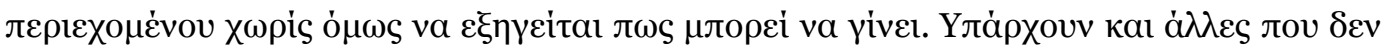

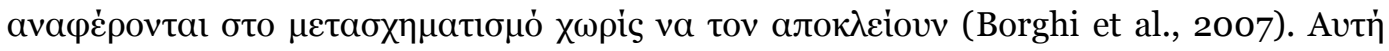

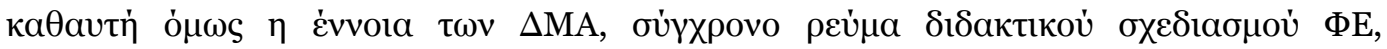

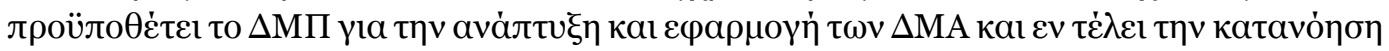

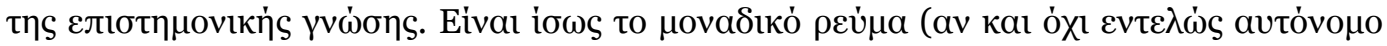

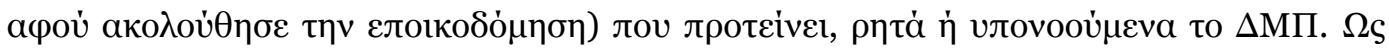

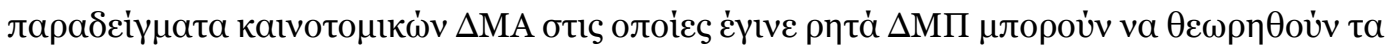

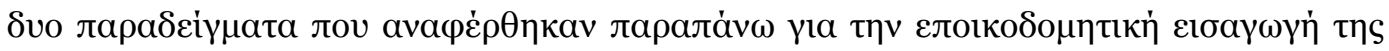

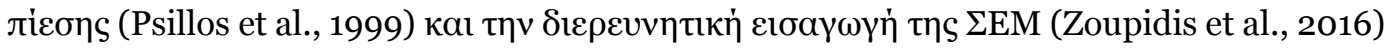

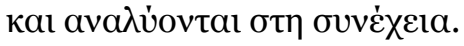




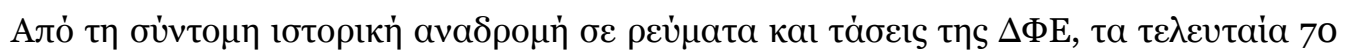

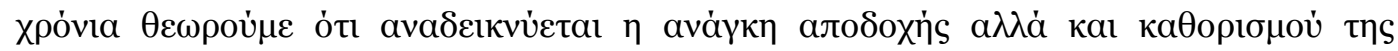

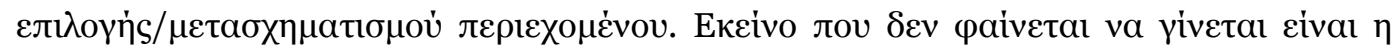

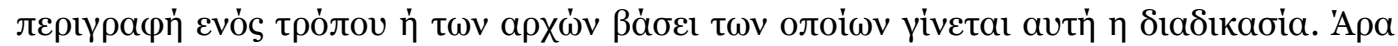

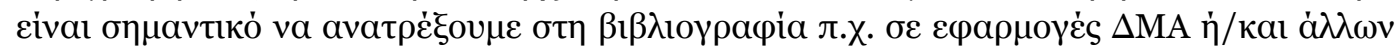

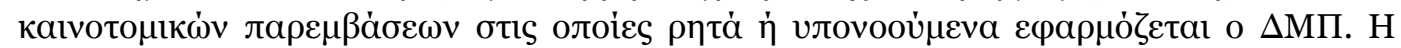

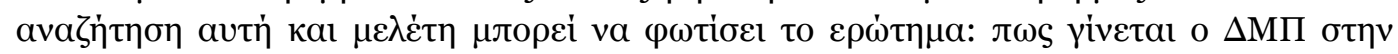

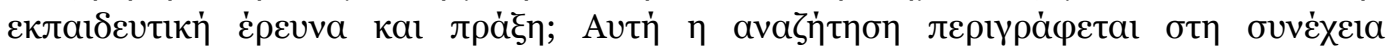

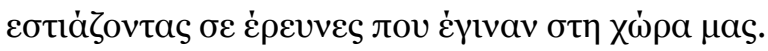

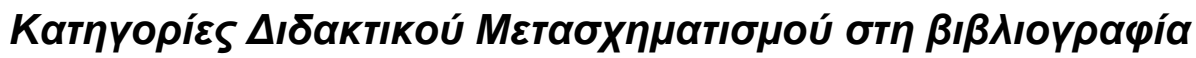

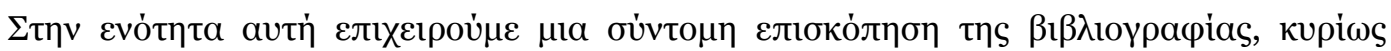

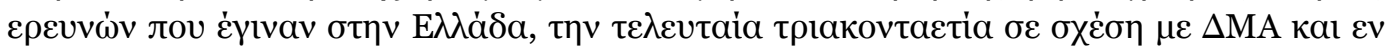

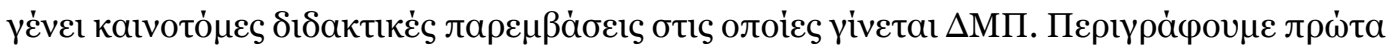

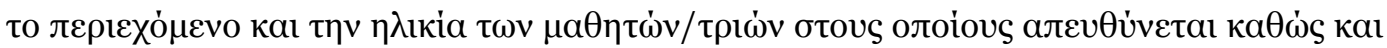

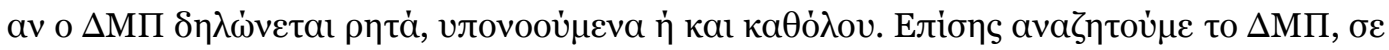

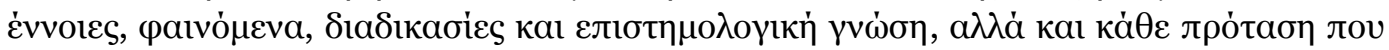

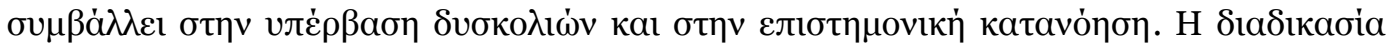

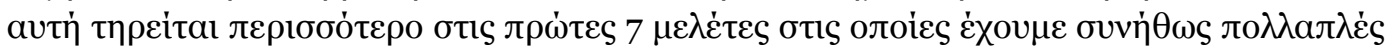

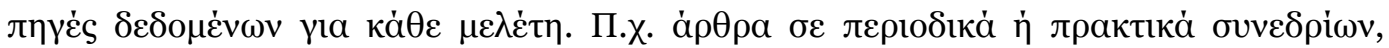

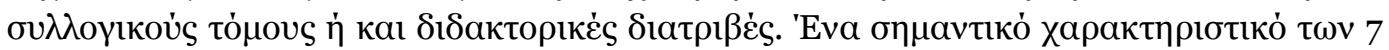

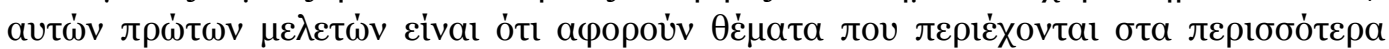

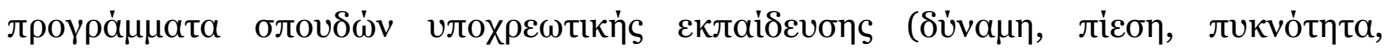

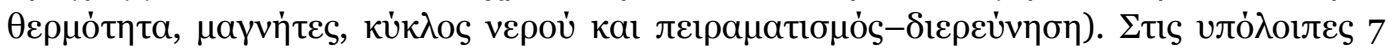

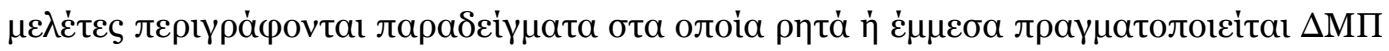

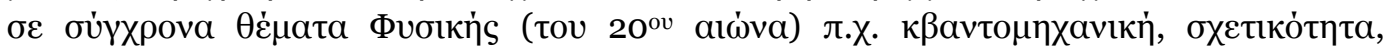

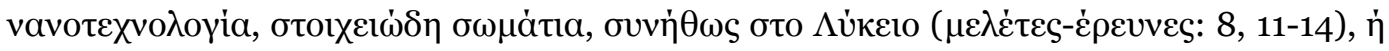

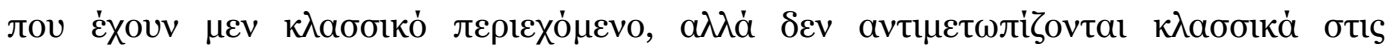

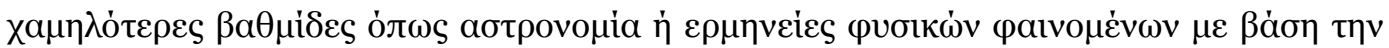

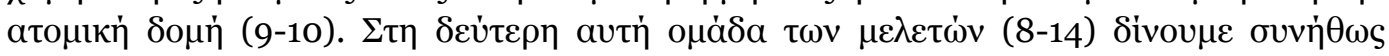

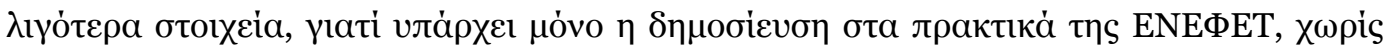

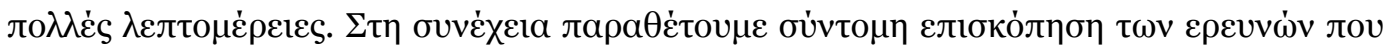

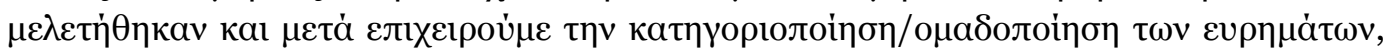

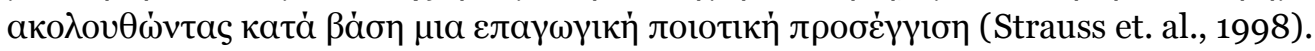

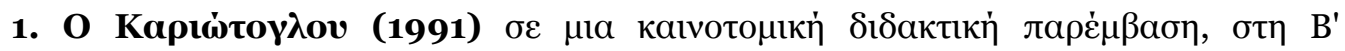

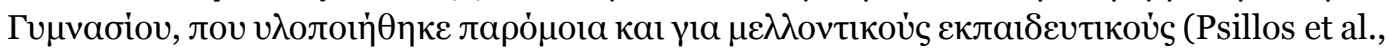

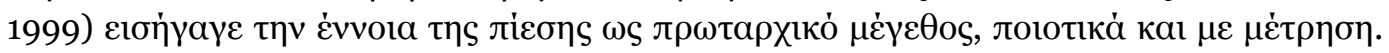

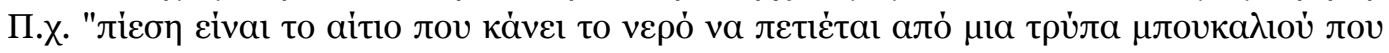

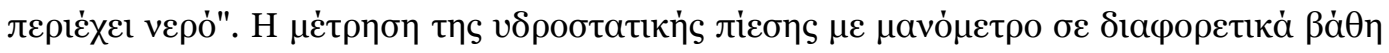




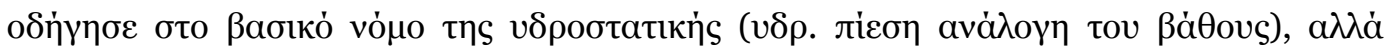

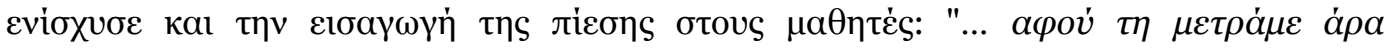

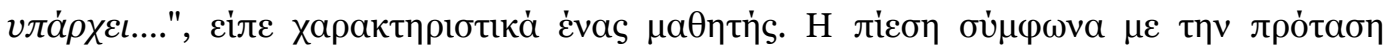

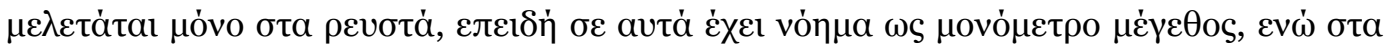

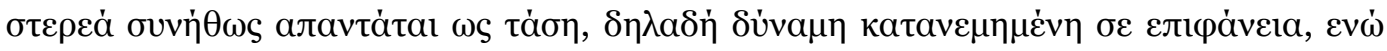

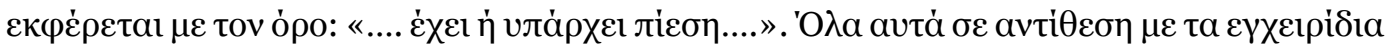

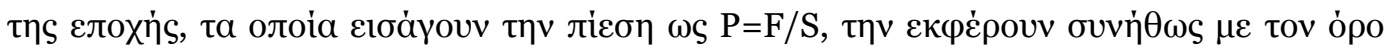

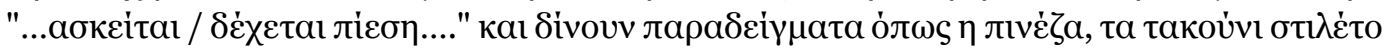

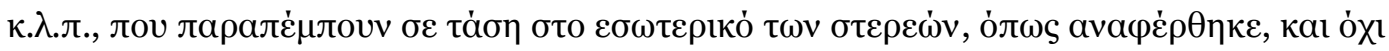

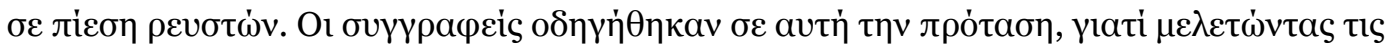

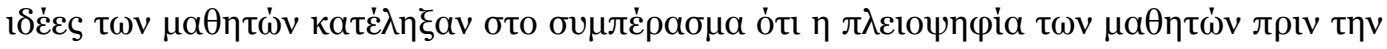

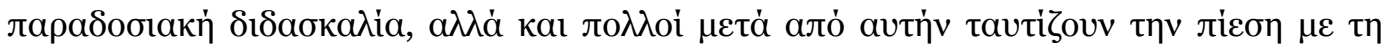

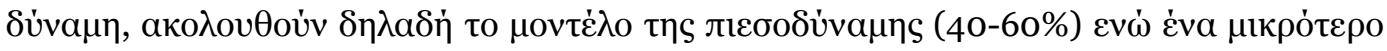

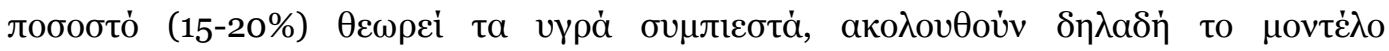

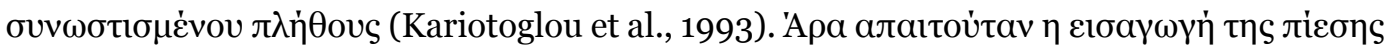

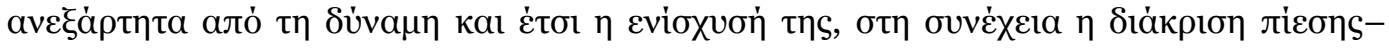

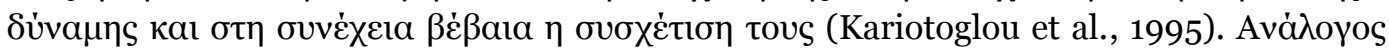

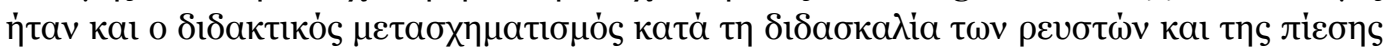

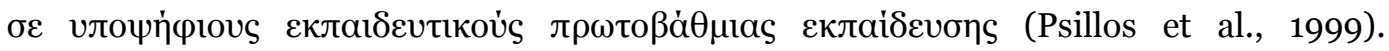

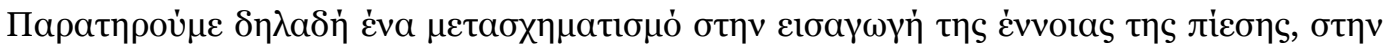

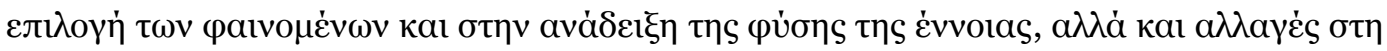

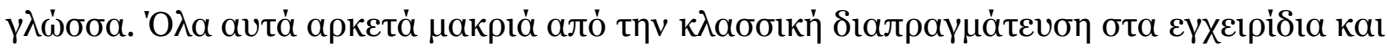

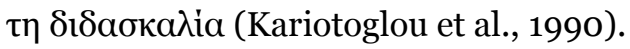

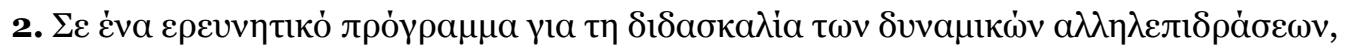

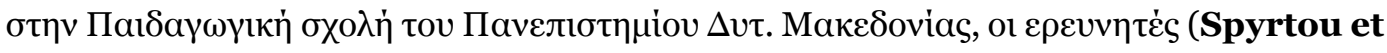

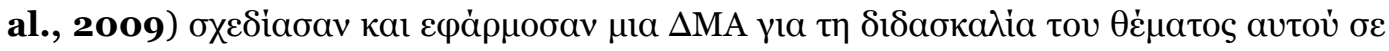

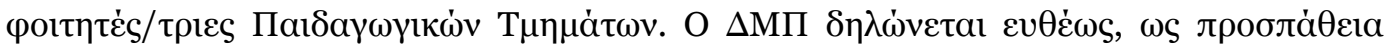

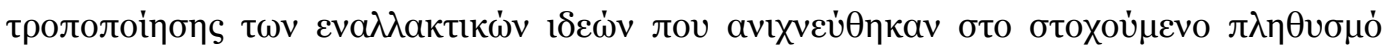

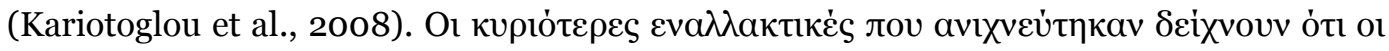

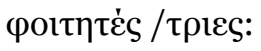

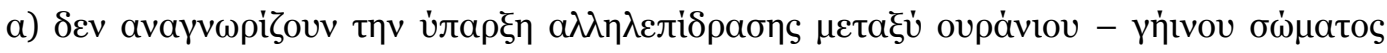

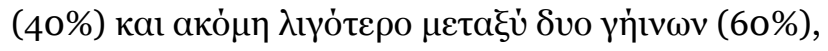

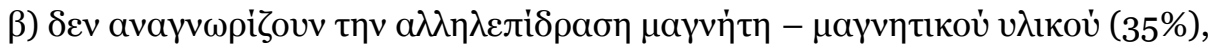

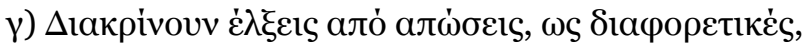

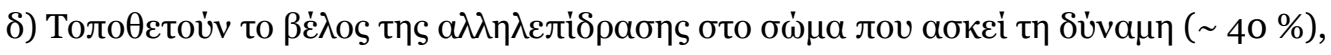

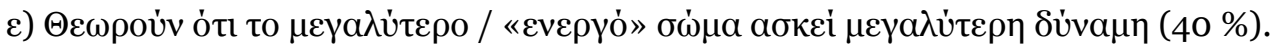

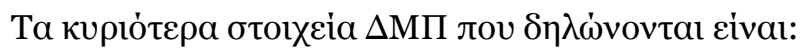




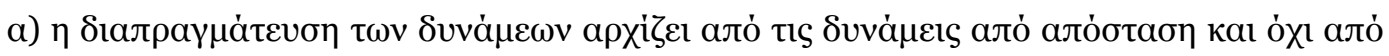

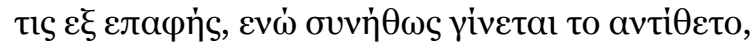

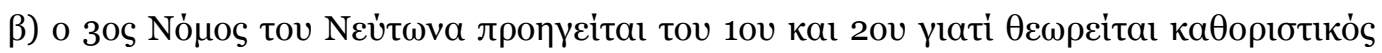

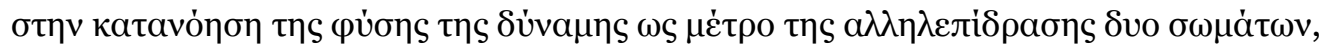

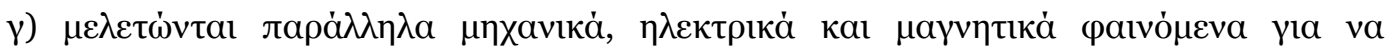

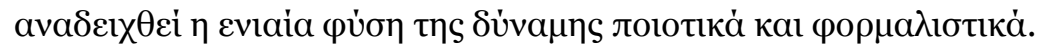

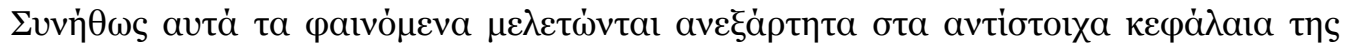

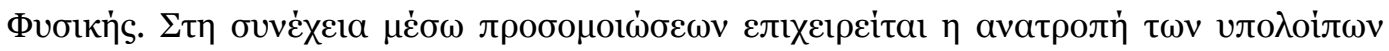

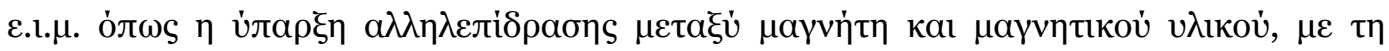

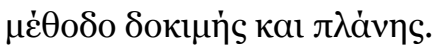

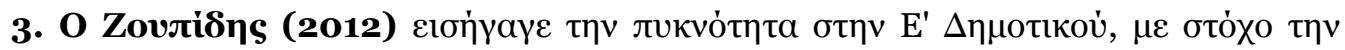

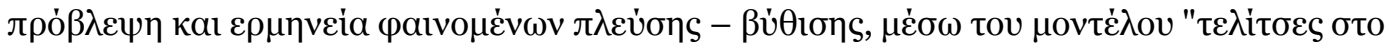

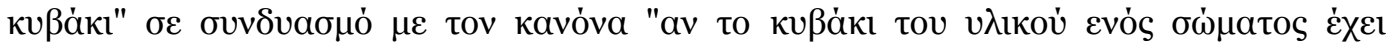

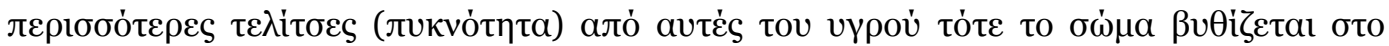

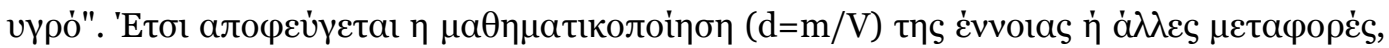

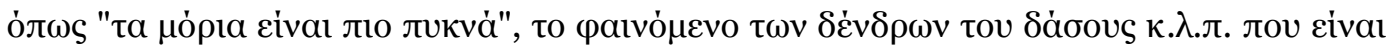

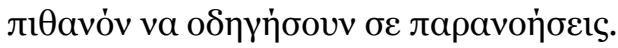

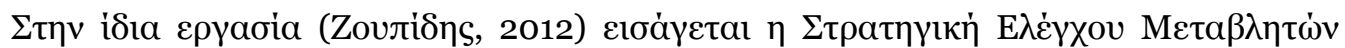

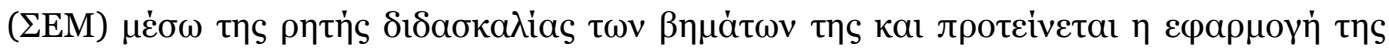

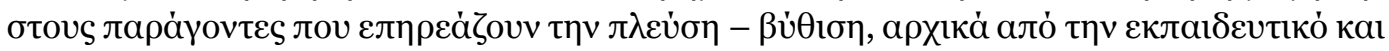

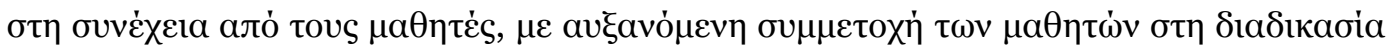

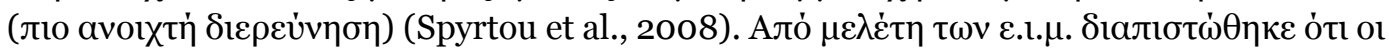

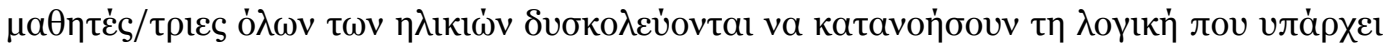

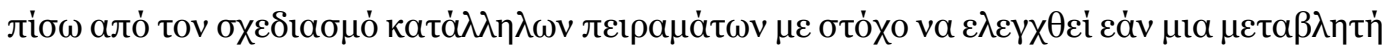

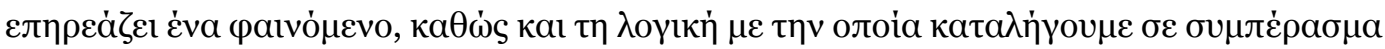

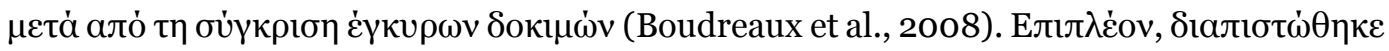

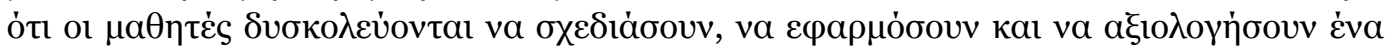

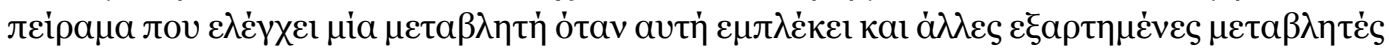

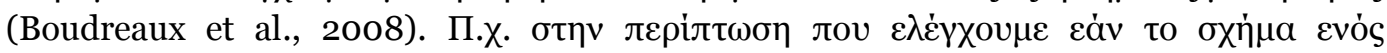

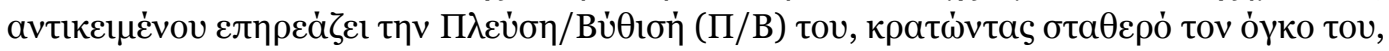

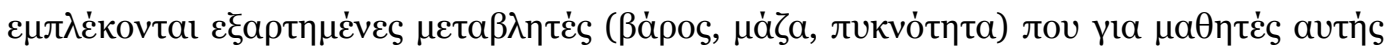

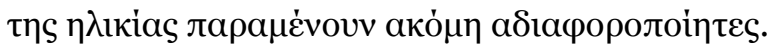

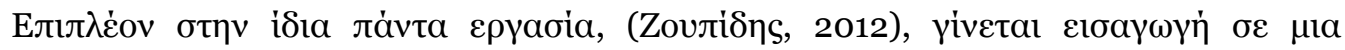

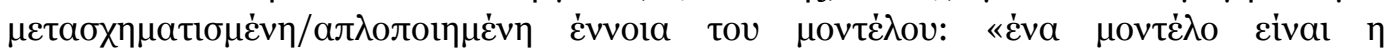

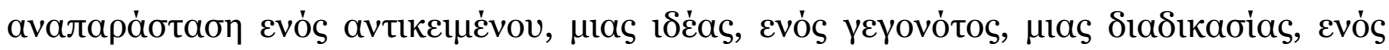

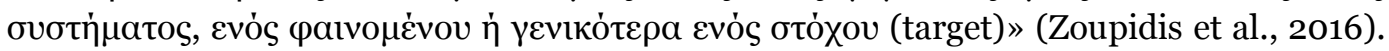

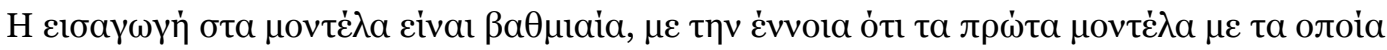

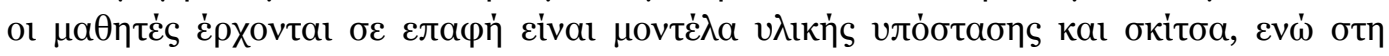




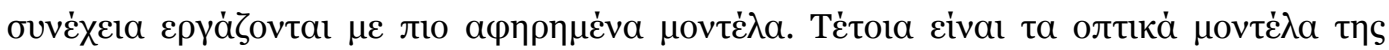

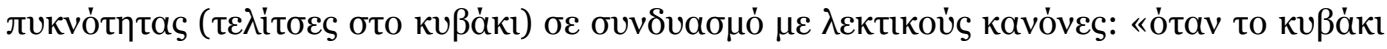

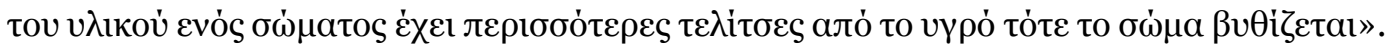

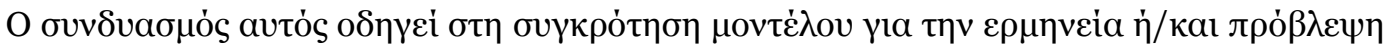

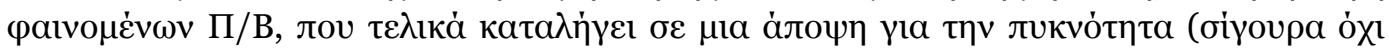

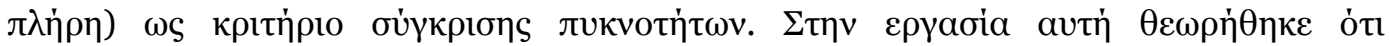

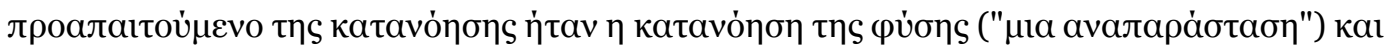

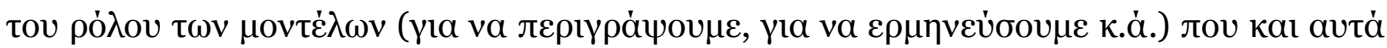

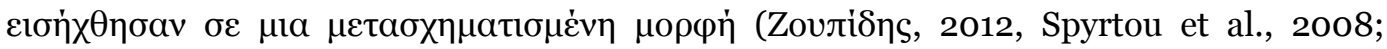
Zoupidis et al., 2016).

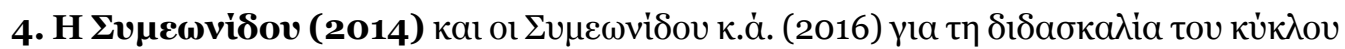

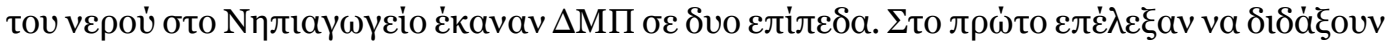

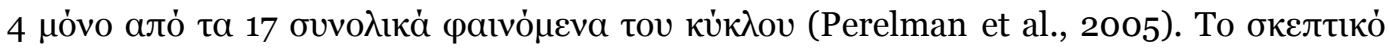

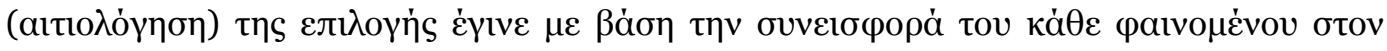

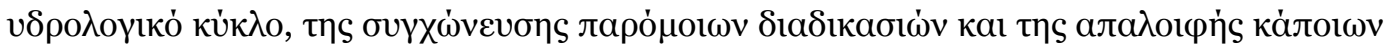

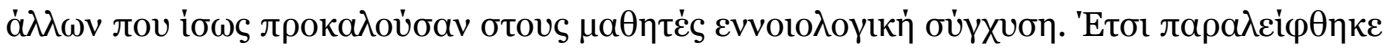

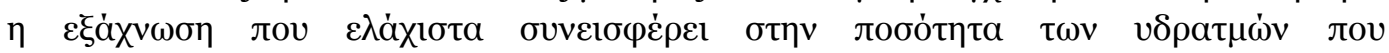

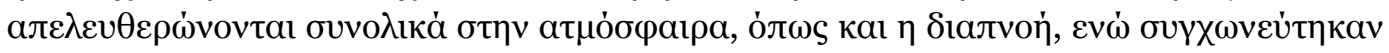

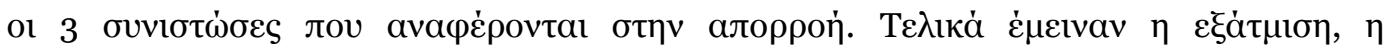

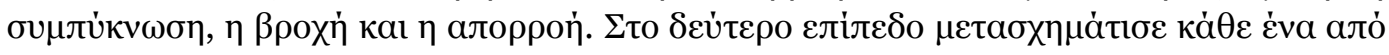

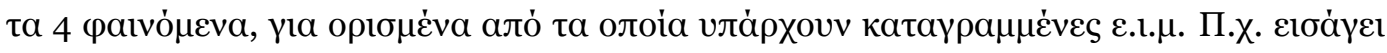

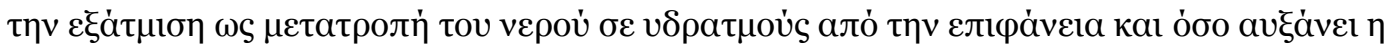

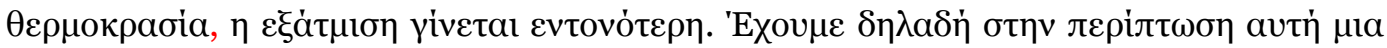

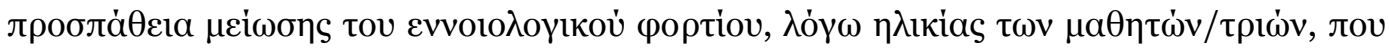

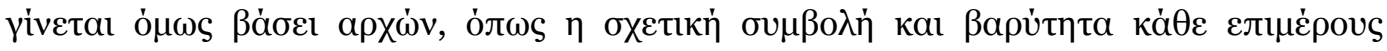

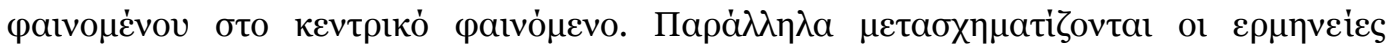

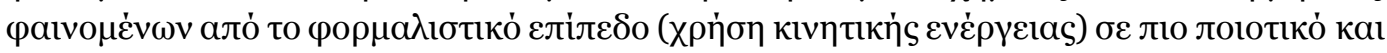

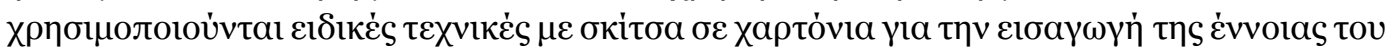

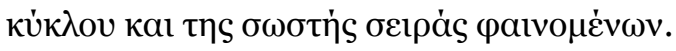

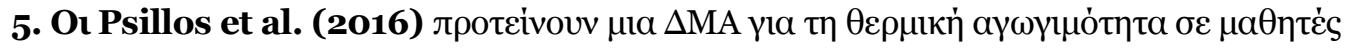

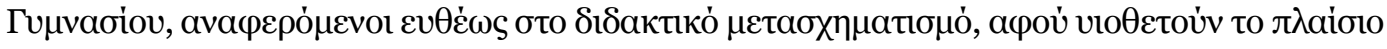

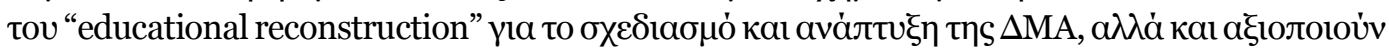

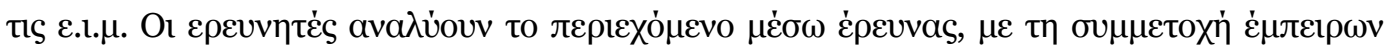

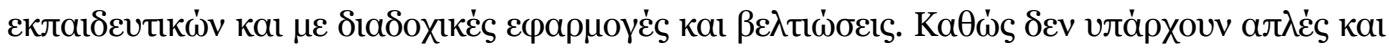

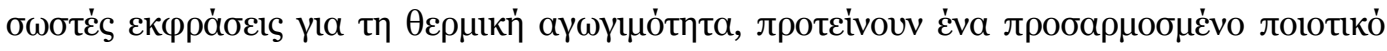

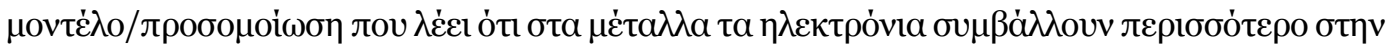

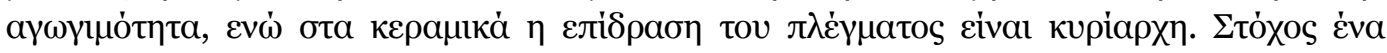

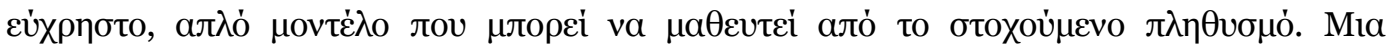




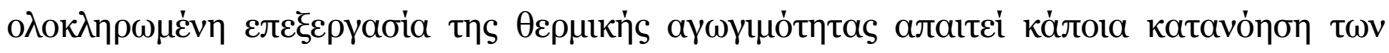

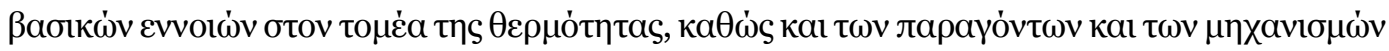

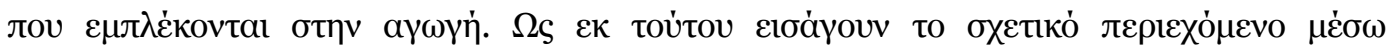

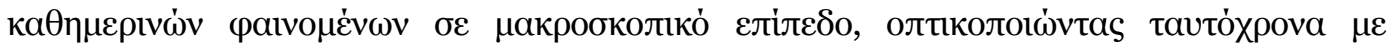

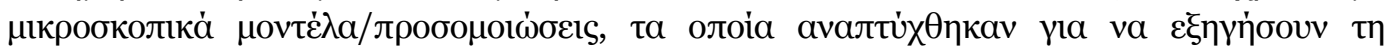

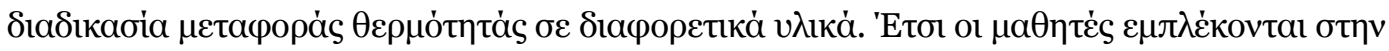

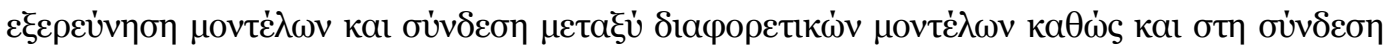

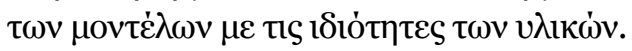

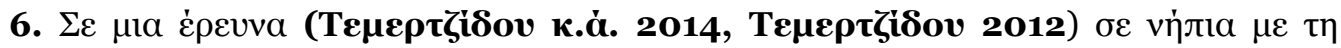

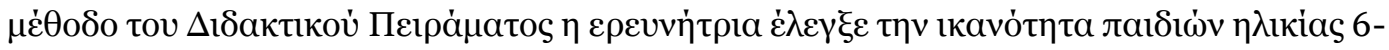

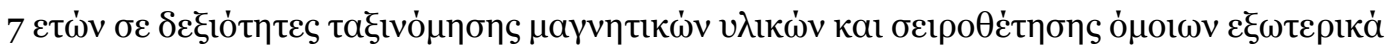

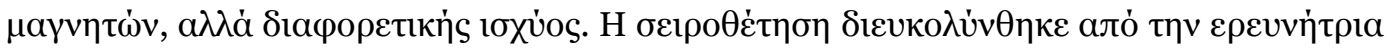

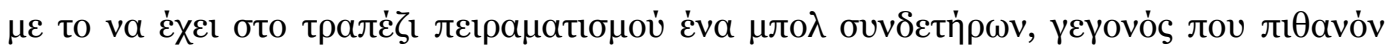

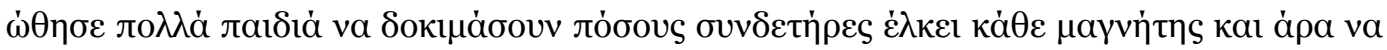

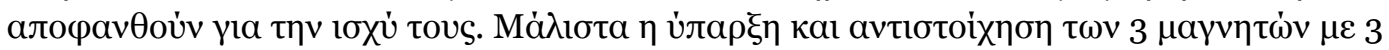

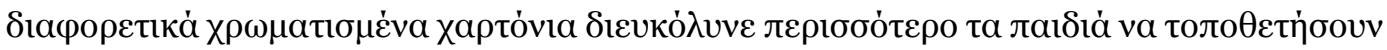

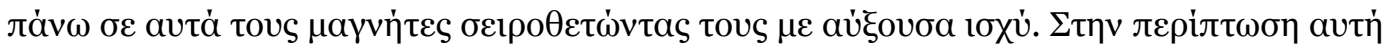

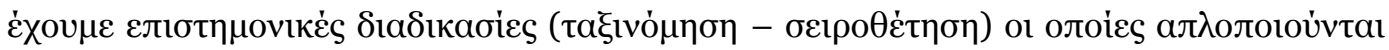

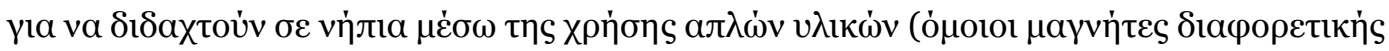

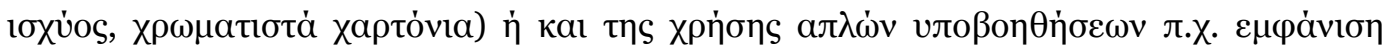

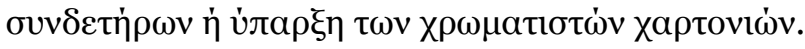

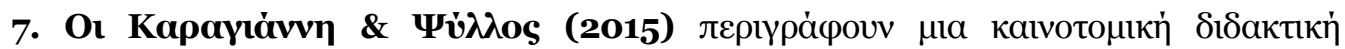

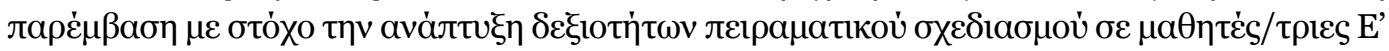

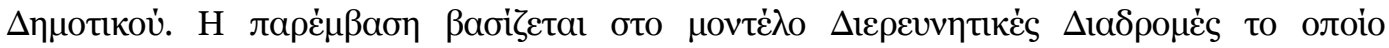

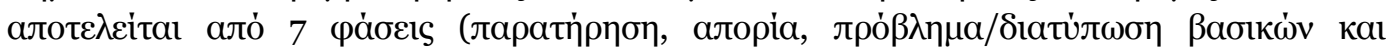

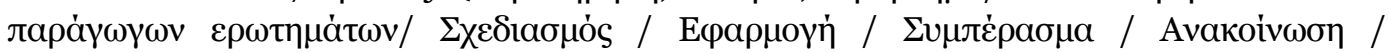

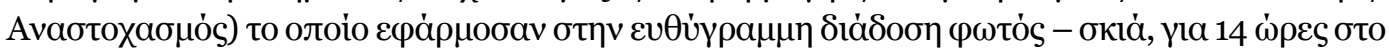

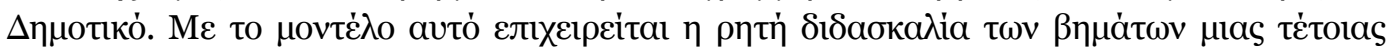

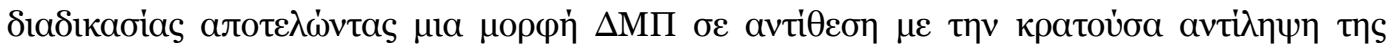

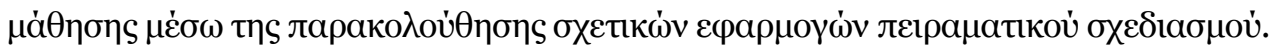

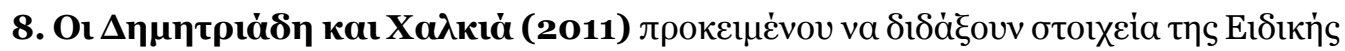

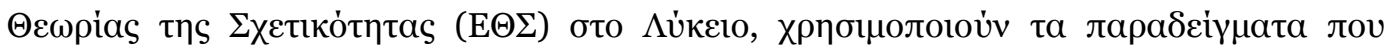

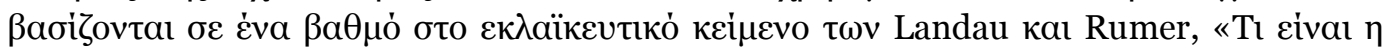

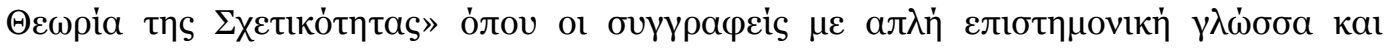

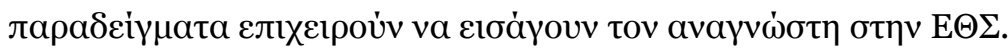




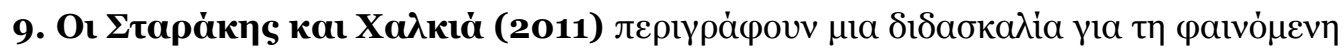

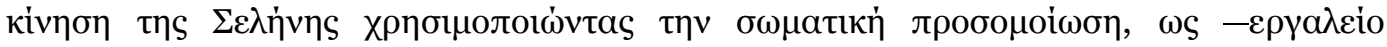

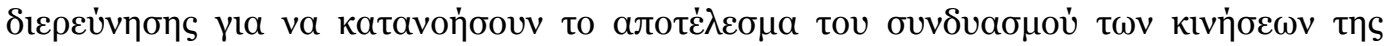

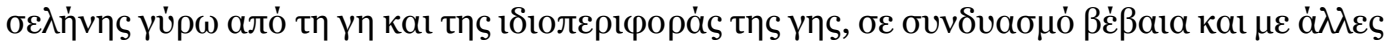

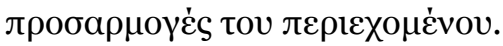

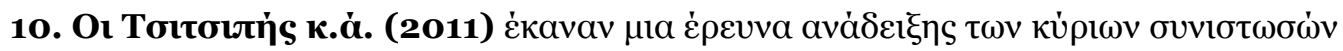

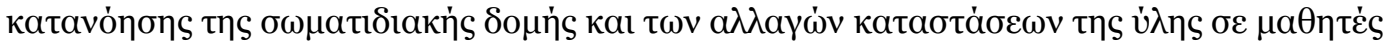

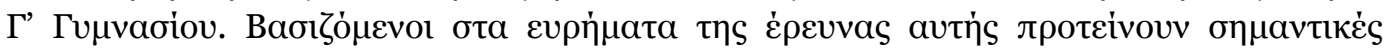

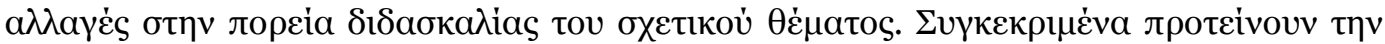

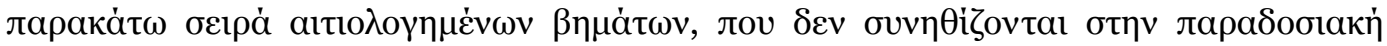

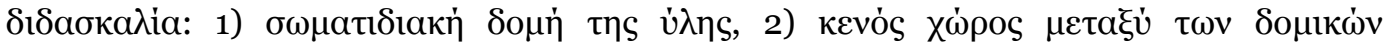

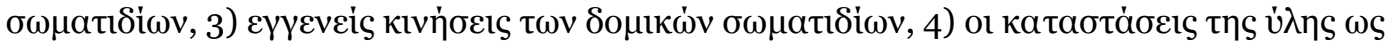

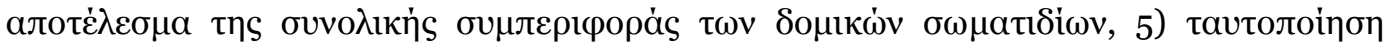

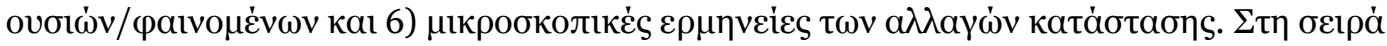

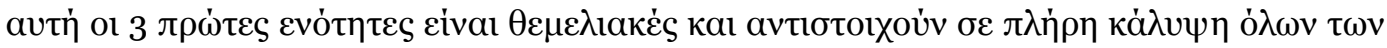

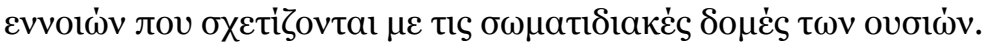

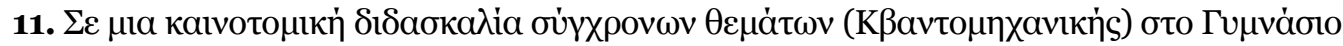

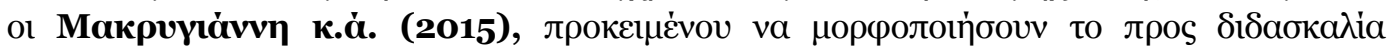

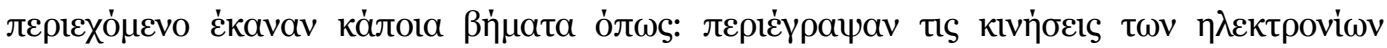

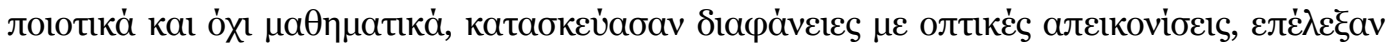

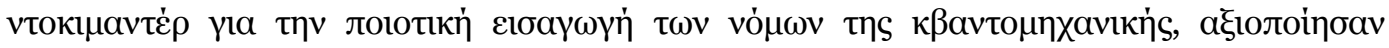

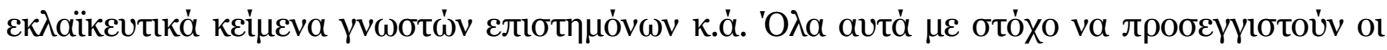

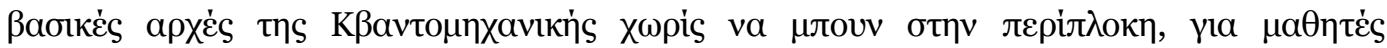

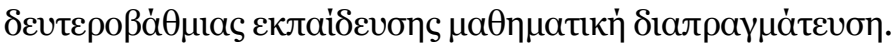

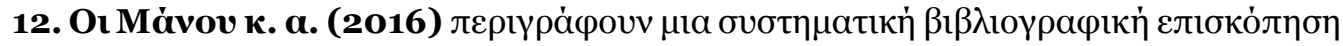

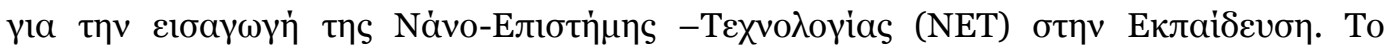

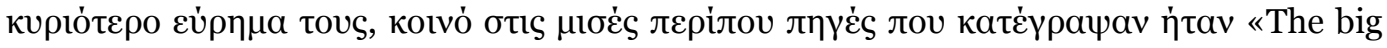

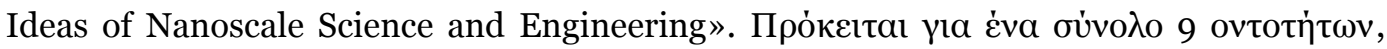

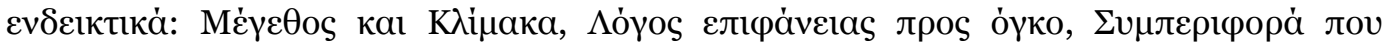

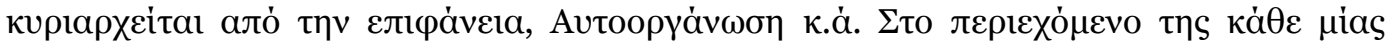

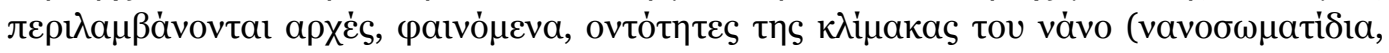

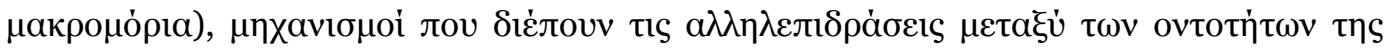

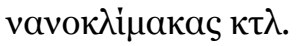

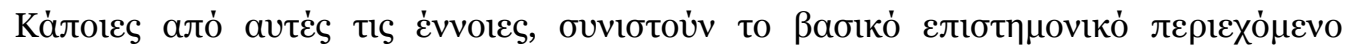

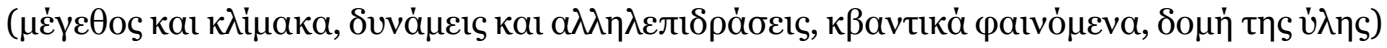

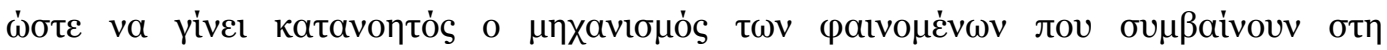




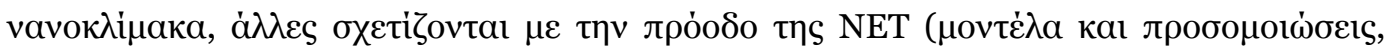

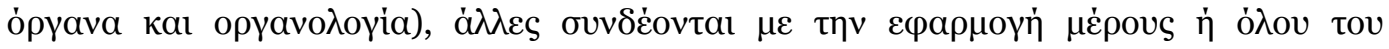

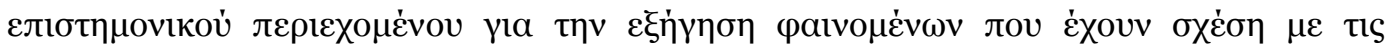

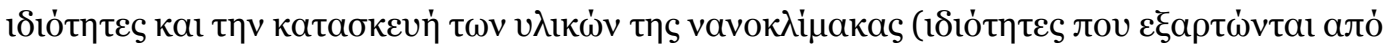

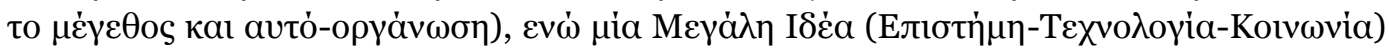

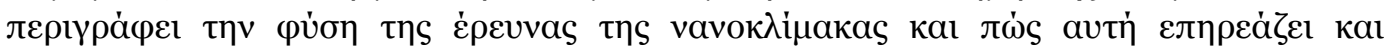

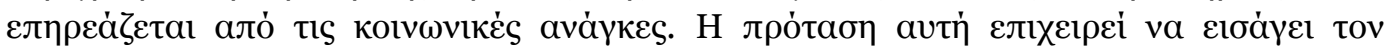

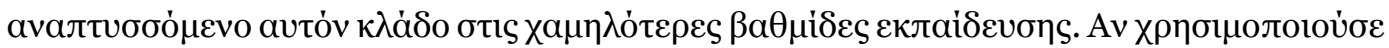

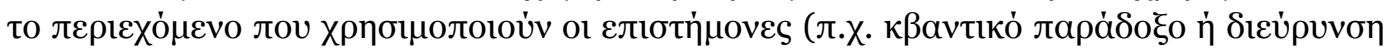

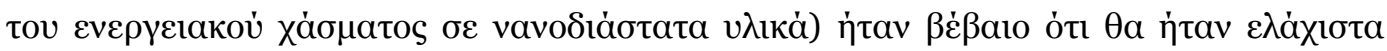

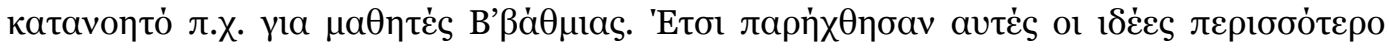

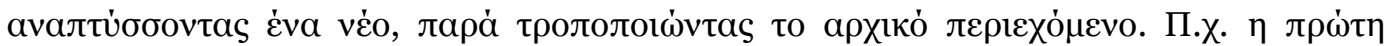

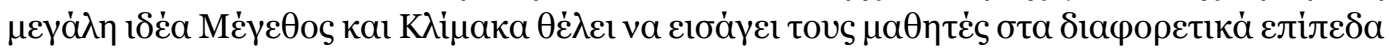

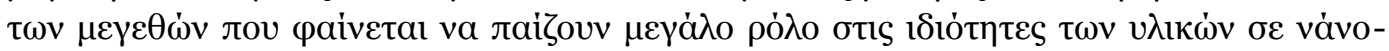

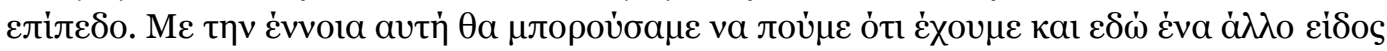

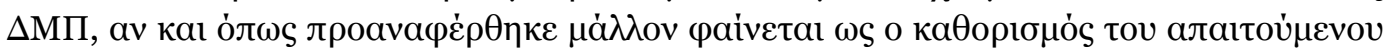

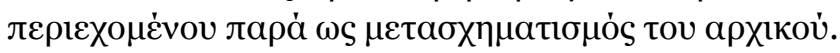

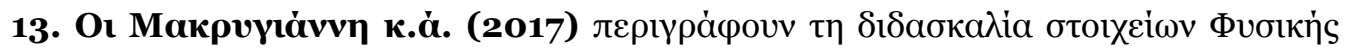

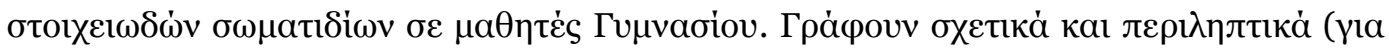

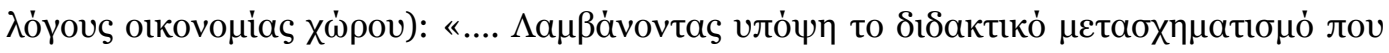

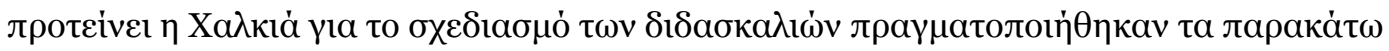
$\beta \grave{\eta} \mu \alpha \tau \alpha:$

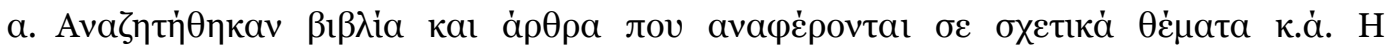

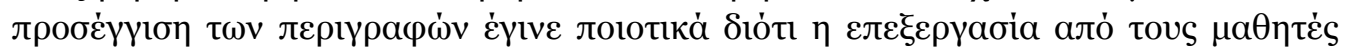

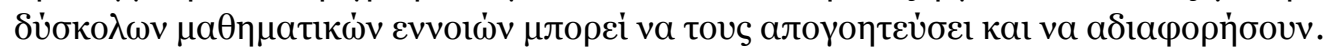

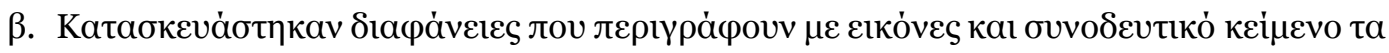

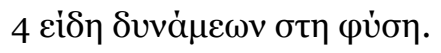

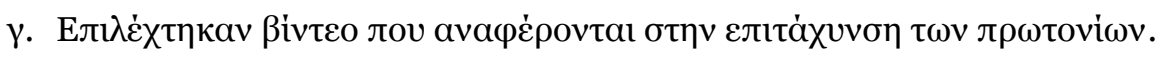

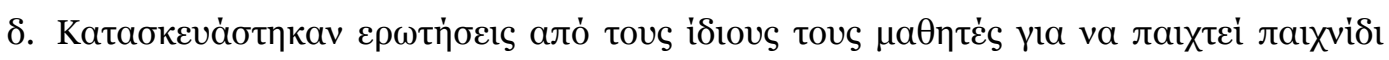
$\varepsilon \rho \omega \tau \dot{\sigma} \sigma \varepsilon \omega \mathrm{v} \mu \varepsilon \tau \alpha \xi \dot{v}$ tous...».

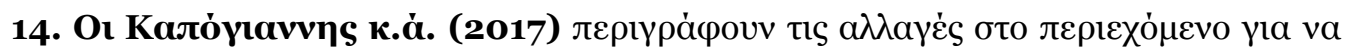

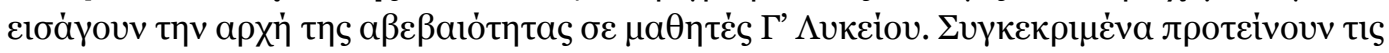

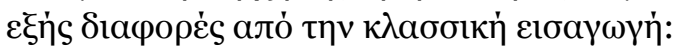

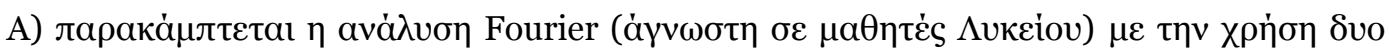

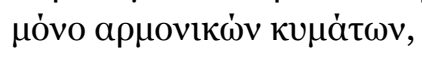




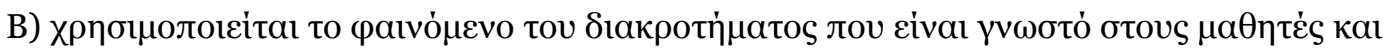

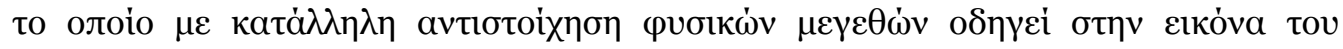

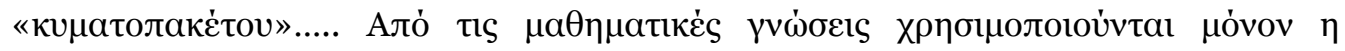

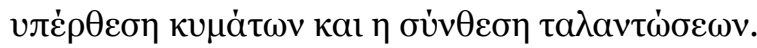

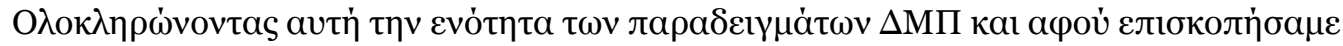

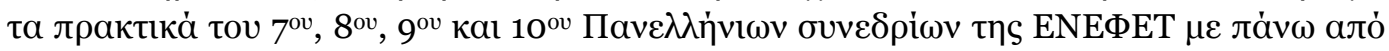

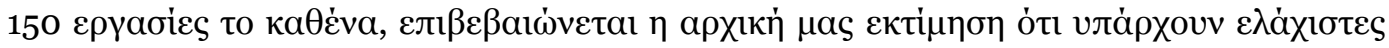

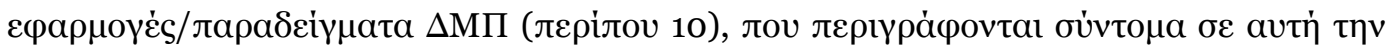

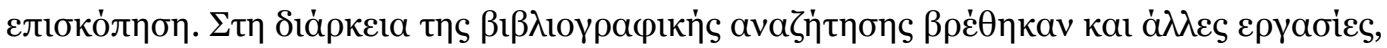

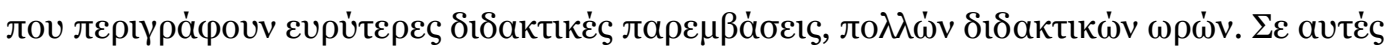

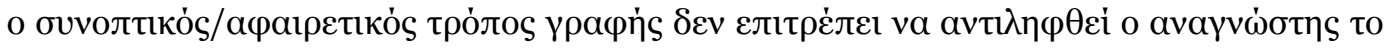

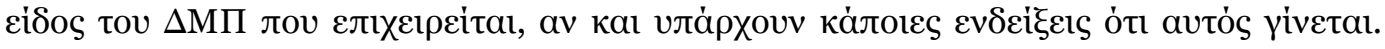

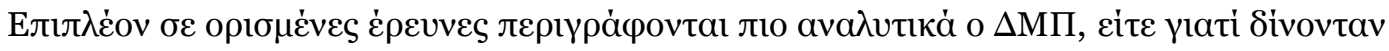

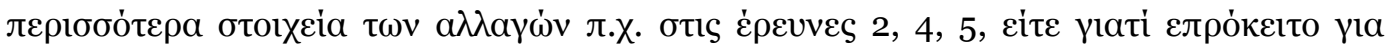

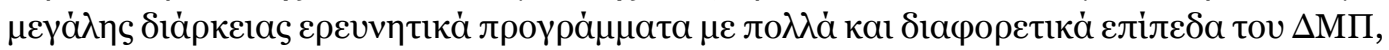

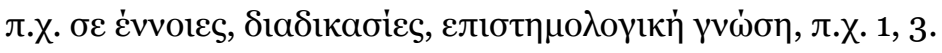

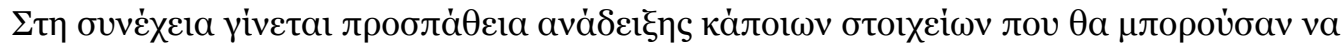

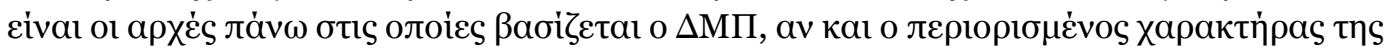

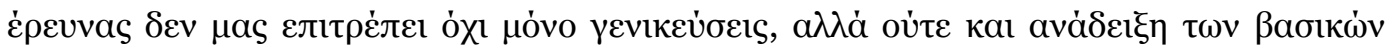

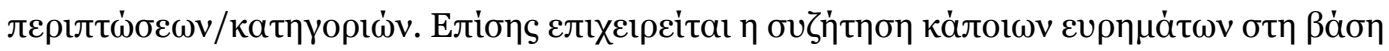

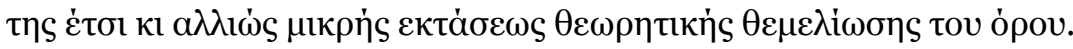

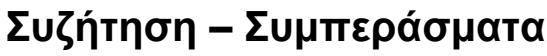

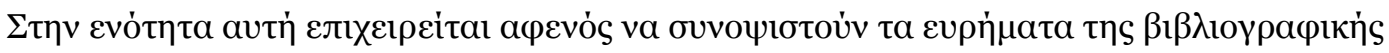

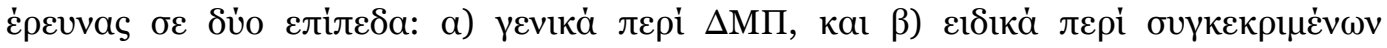

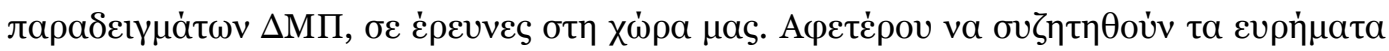

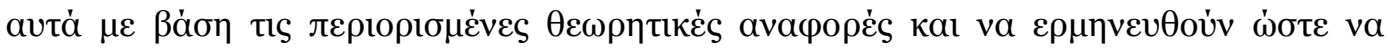

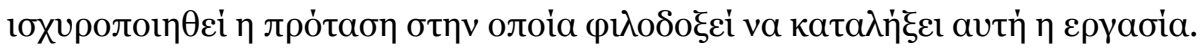

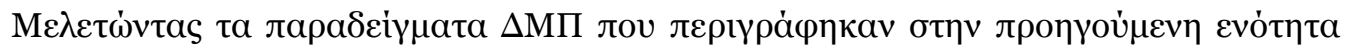

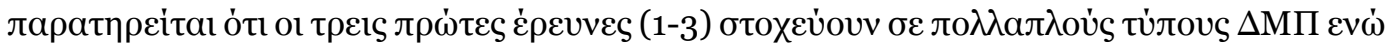

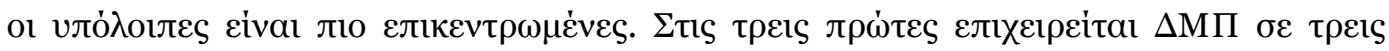

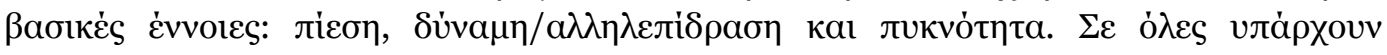

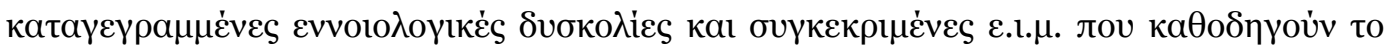
$\Delta \mathrm{M}$.

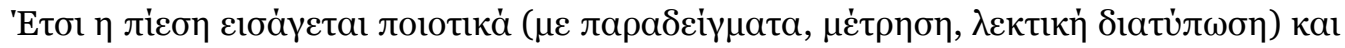

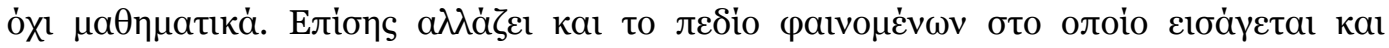

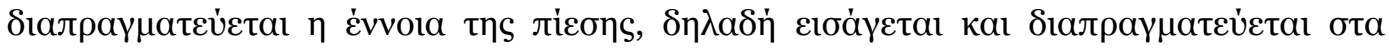

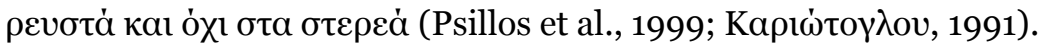




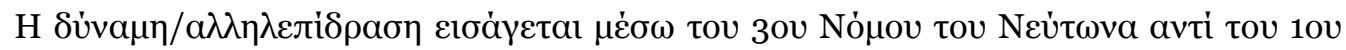

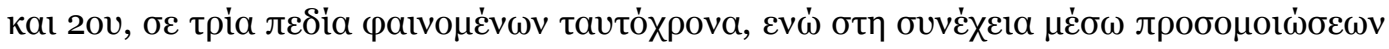

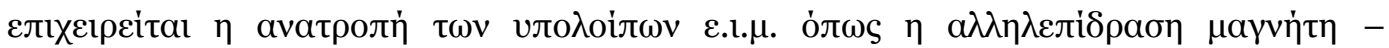
$\mu \alpha \gamma v \eta \tau \kappa$ ่

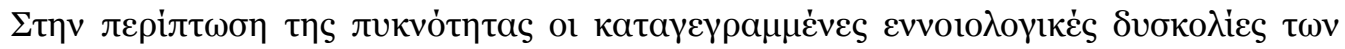

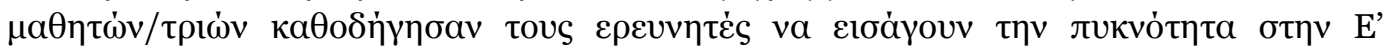

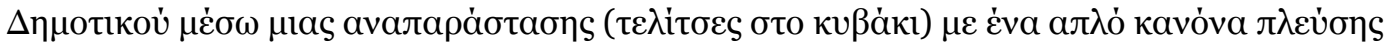

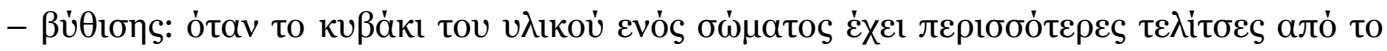

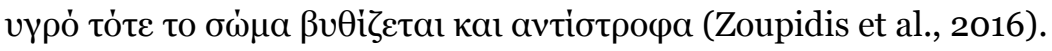

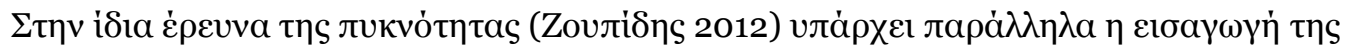

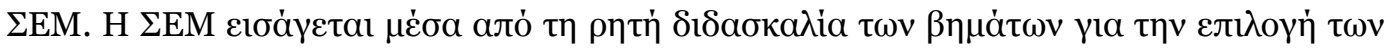

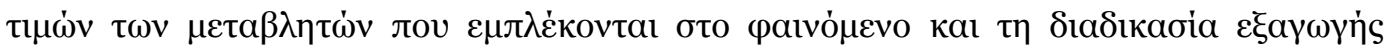

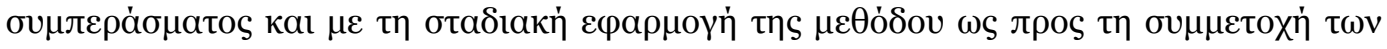
$\mu \alpha \theta \eta \tau \dot{v}$.

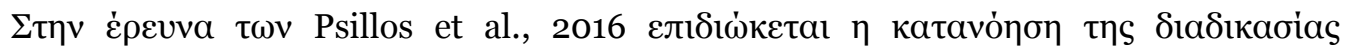

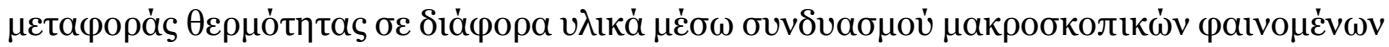

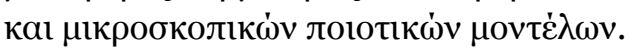

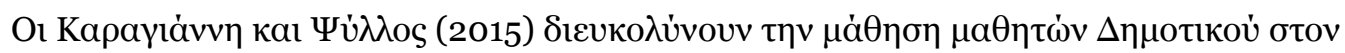

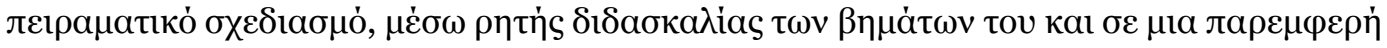

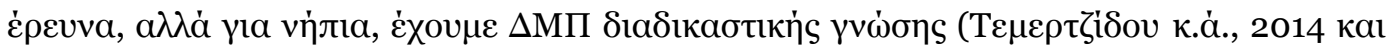

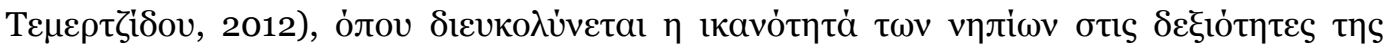

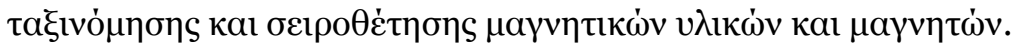

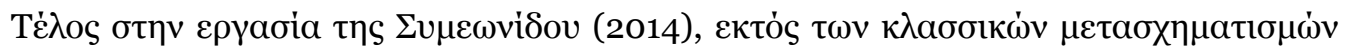

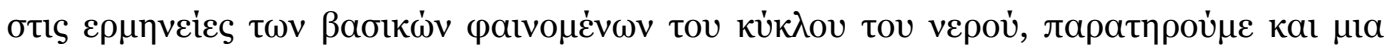

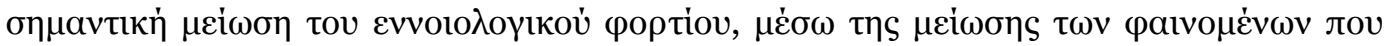

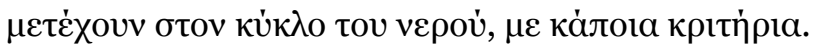

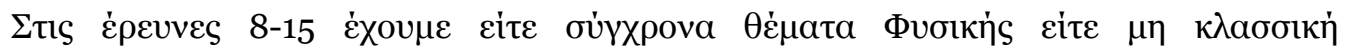

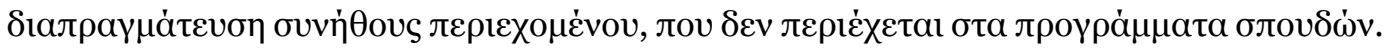

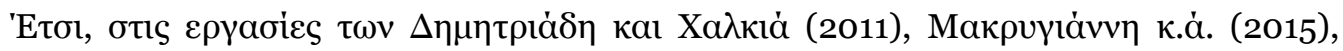

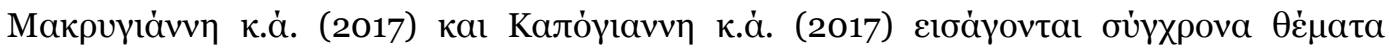

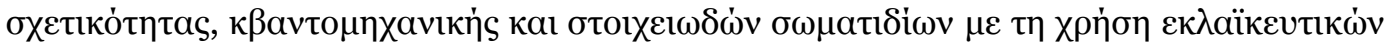

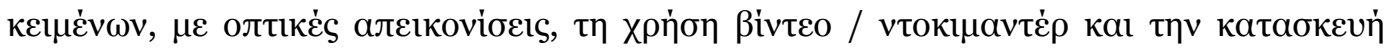

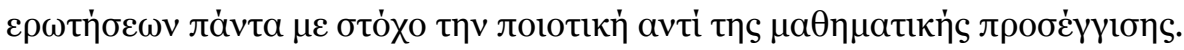

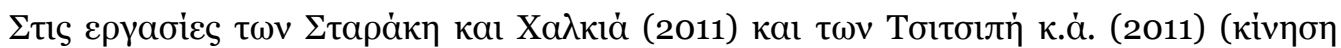

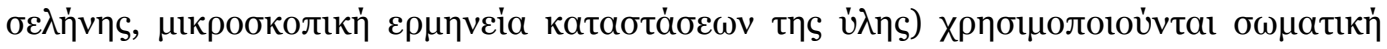

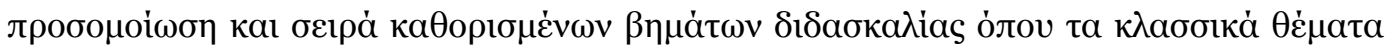

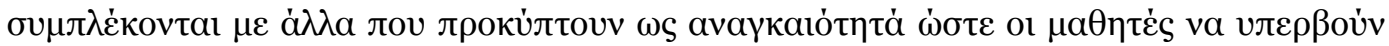

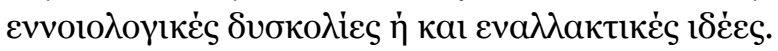




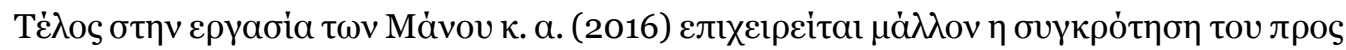

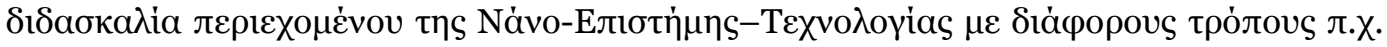

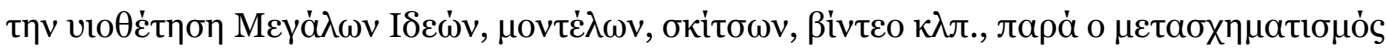

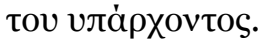

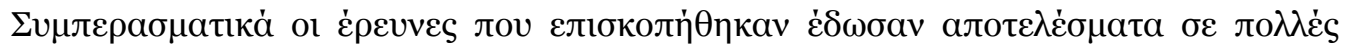

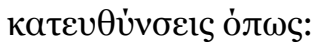

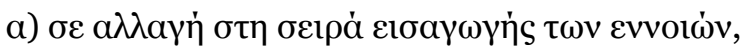

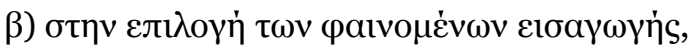

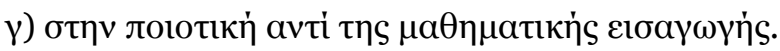

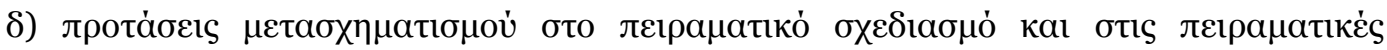

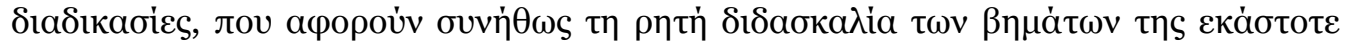
$\mu \varepsilon \theta \dot{\delta} \delta$ ov,

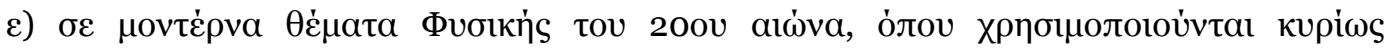

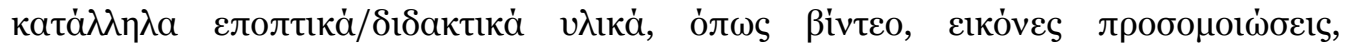
$\varepsilon \kappa \lambda a \ddot{\kappa} \kappa v \tau \tau \kappa \alpha \dot{~ \kappa \varepsilon i \mu \varepsilon \varepsilon v a ~ \kappa \lambda л, ~}$

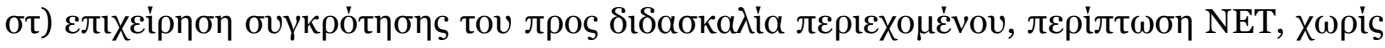

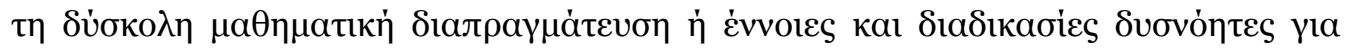
$\mu \alpha \theta \eta \tau \dot{s} \varsigma \mu \iota \kappa \rho \eta \dot{s} \eta \lambda \iota \kappa i a s$.

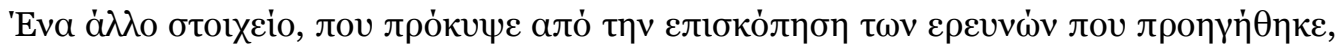

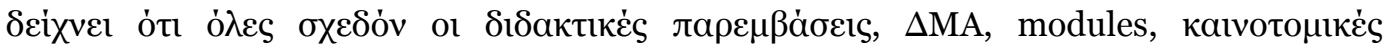

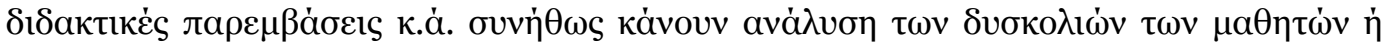

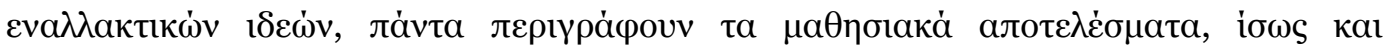

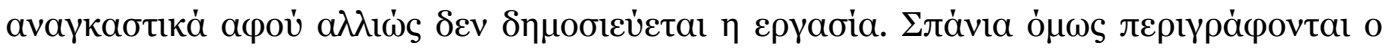

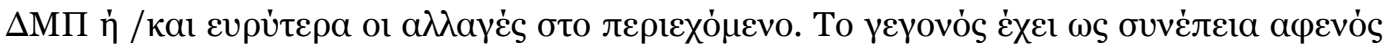

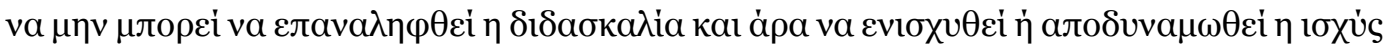

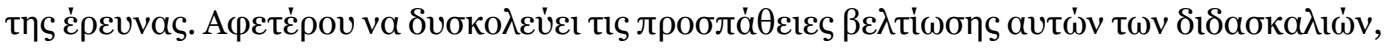
a

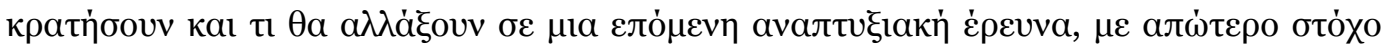

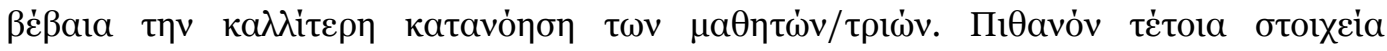

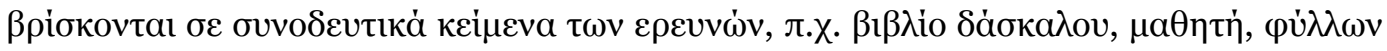

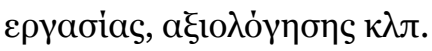

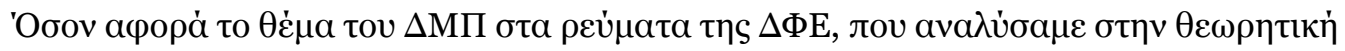

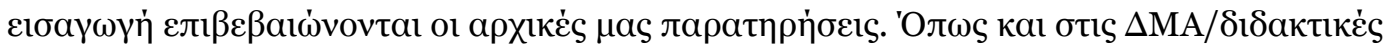

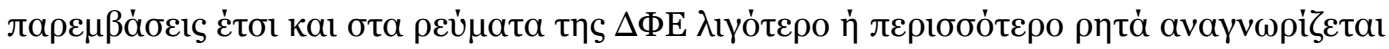

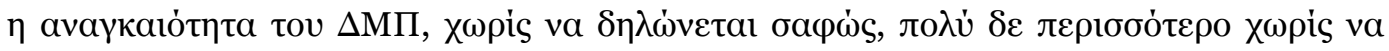
$\varepsilon \overline{\xi \eta \gamma \varepsilon i \tau a l ~ \pi \omega \varsigma ~ \alpha u t o ́ s ~ \gamma i v e \tau a l . ~}$

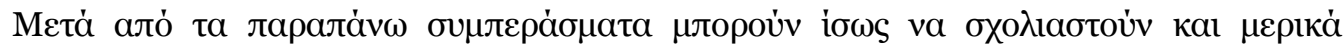

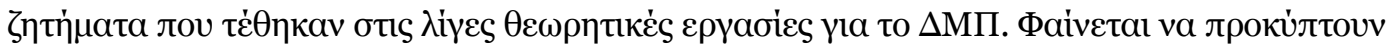

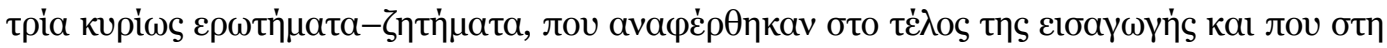




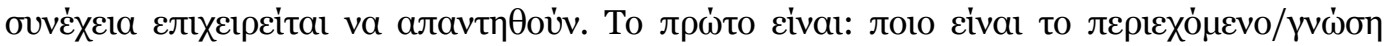

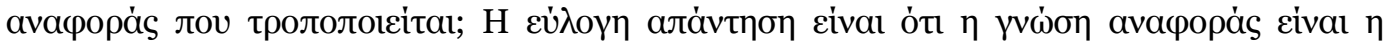

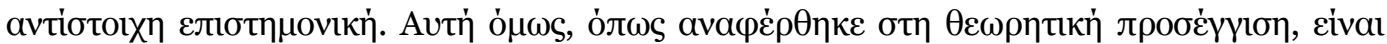

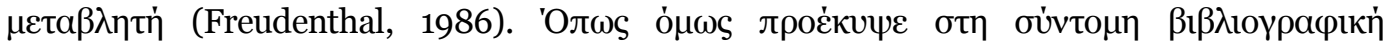

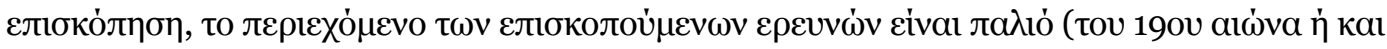

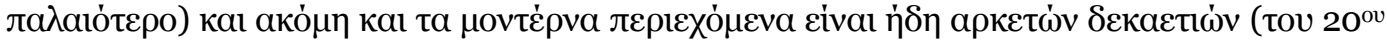

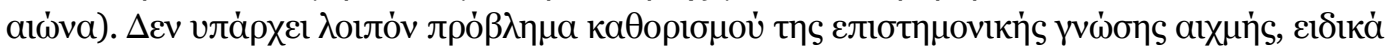

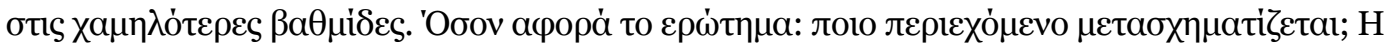

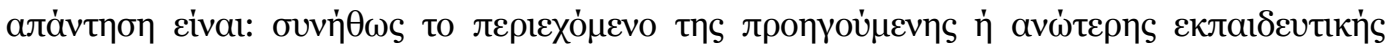

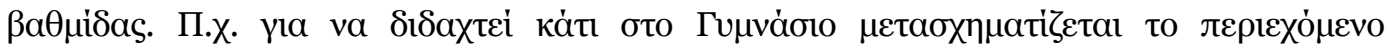

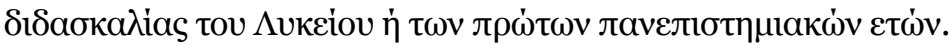

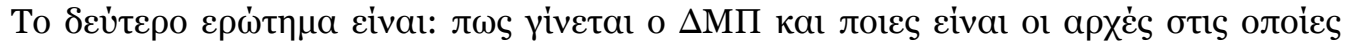

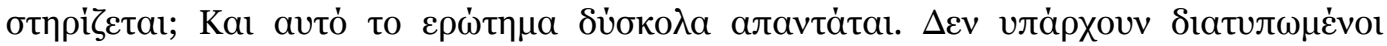

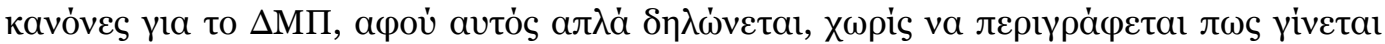

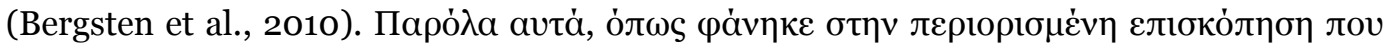

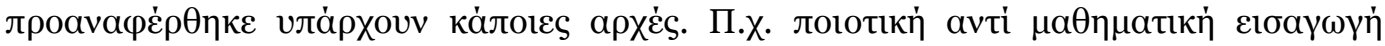

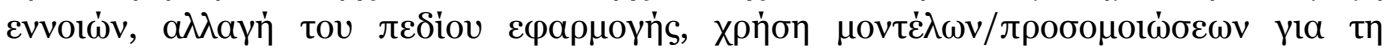

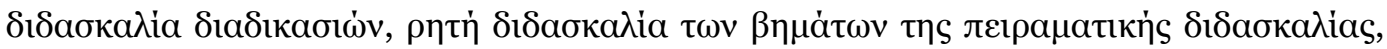

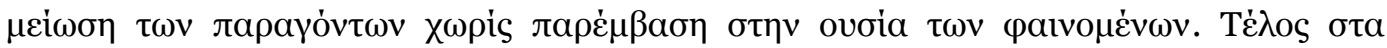

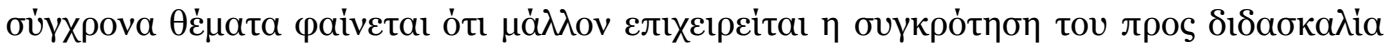

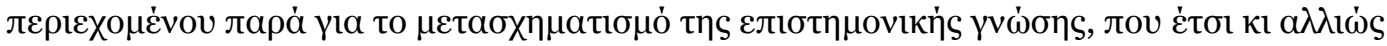

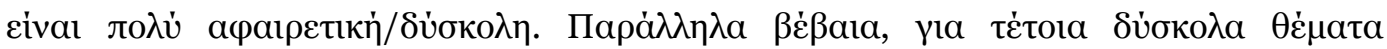

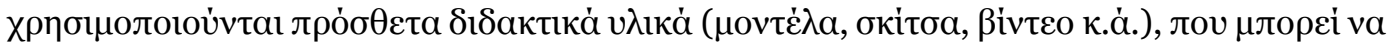

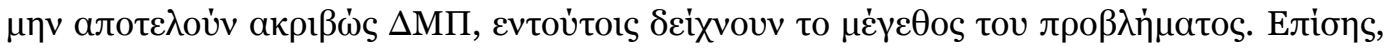

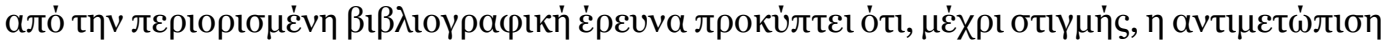

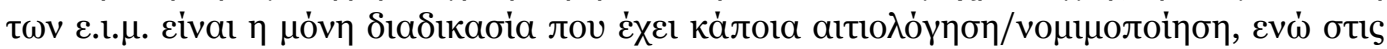

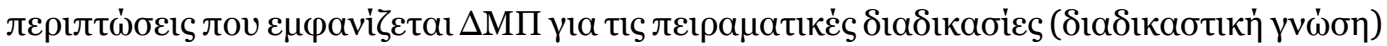

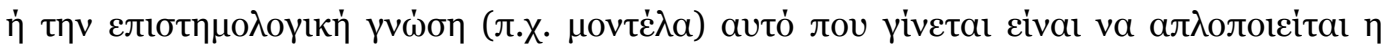

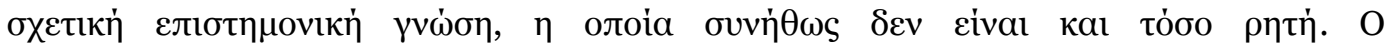

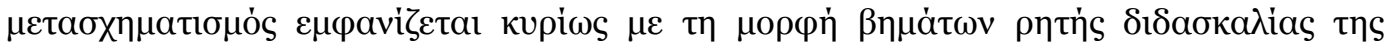

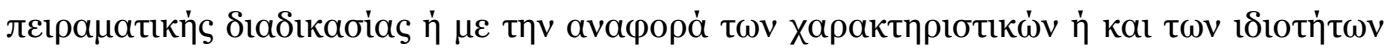

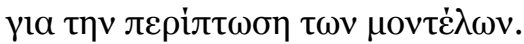

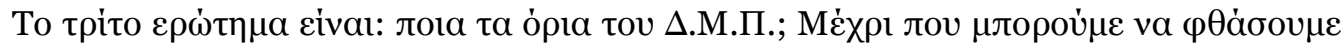

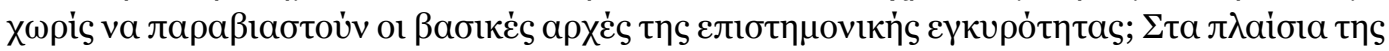

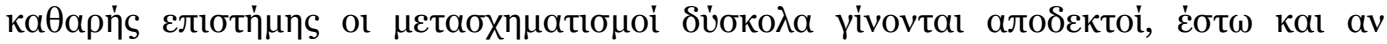

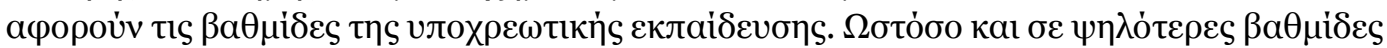

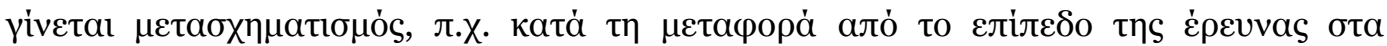

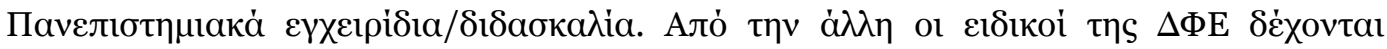

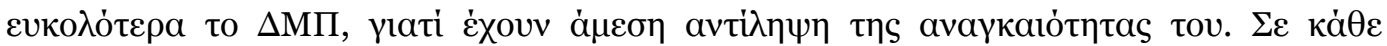

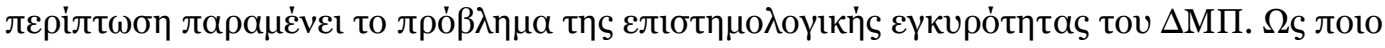




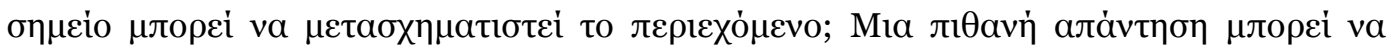

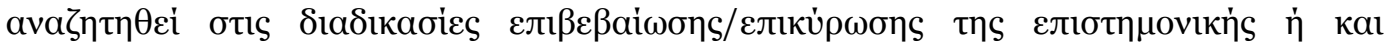

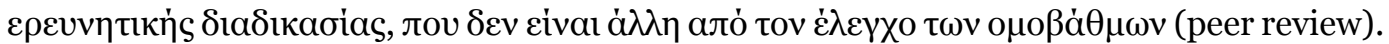

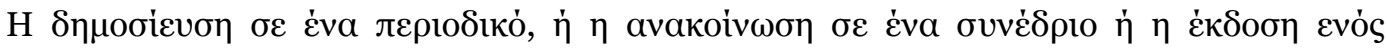

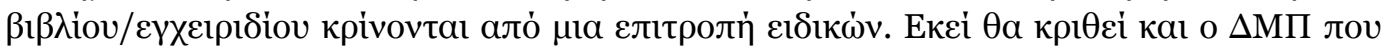

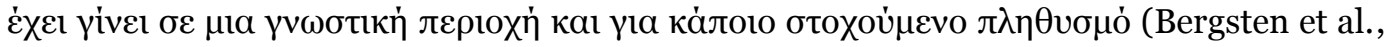

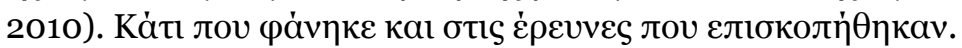

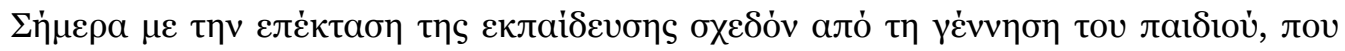

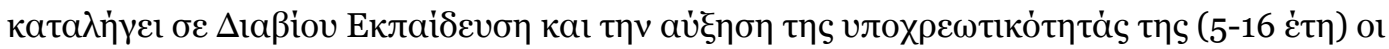

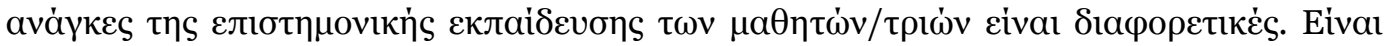

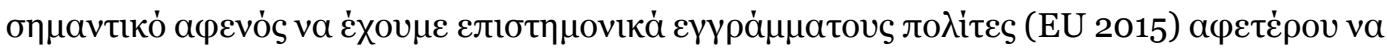

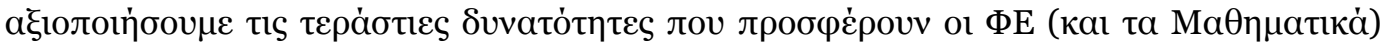

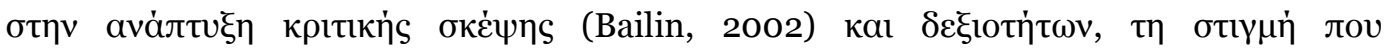

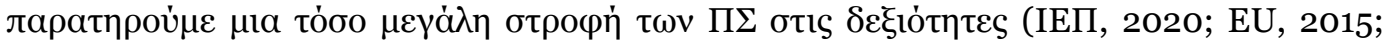

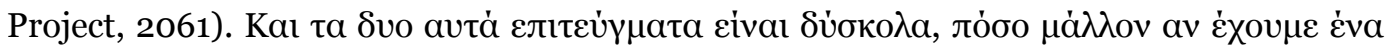

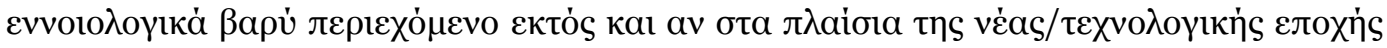

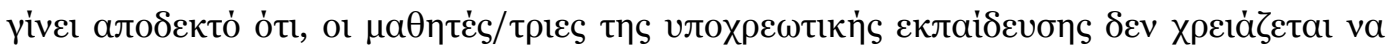

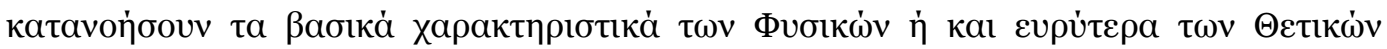

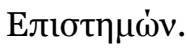

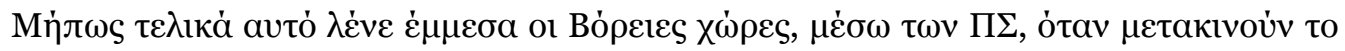

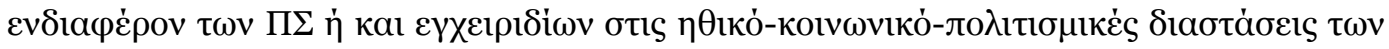

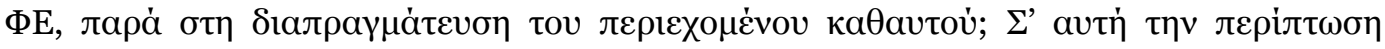

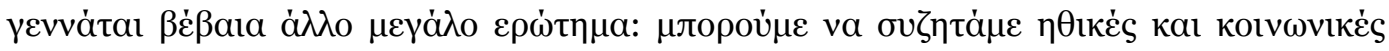

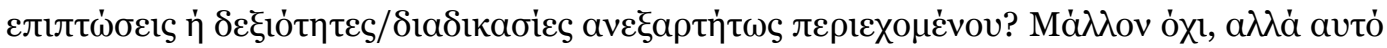

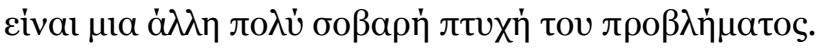

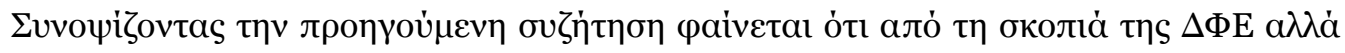

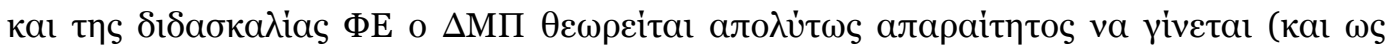

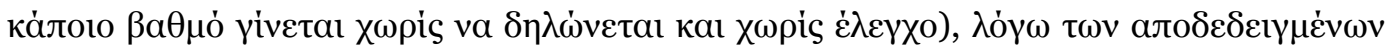

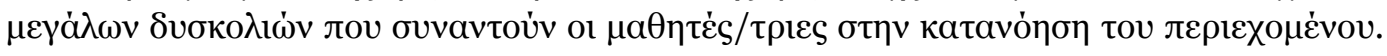

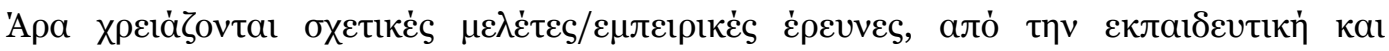

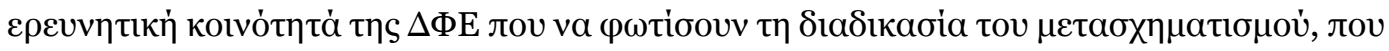

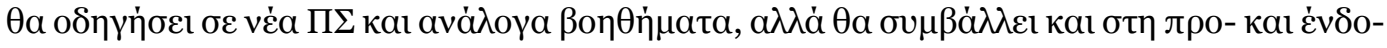

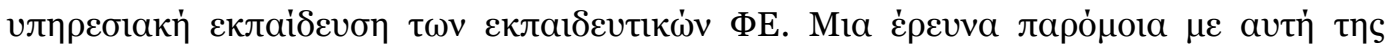

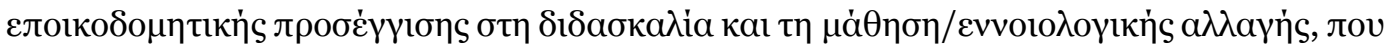

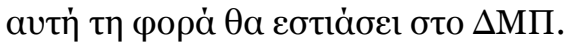

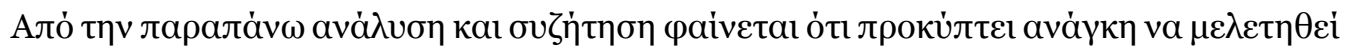

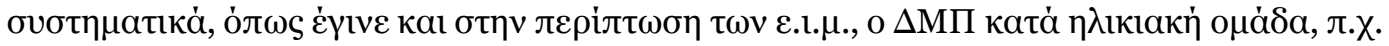

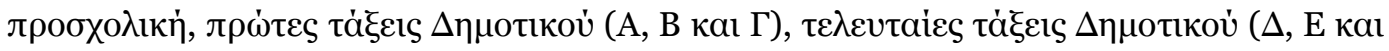

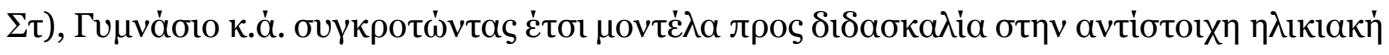

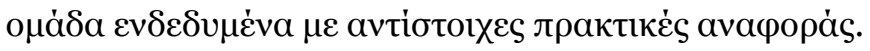




\section{Euxapiotíعs}

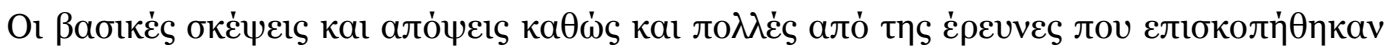

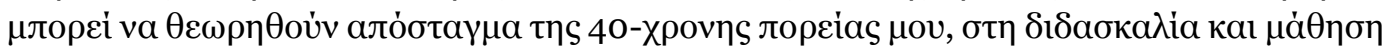

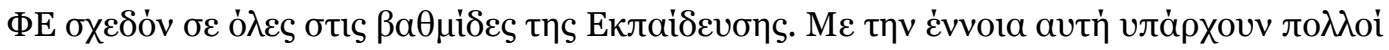

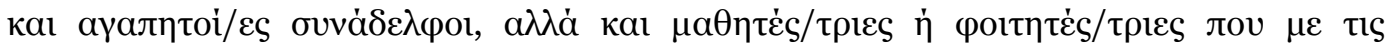

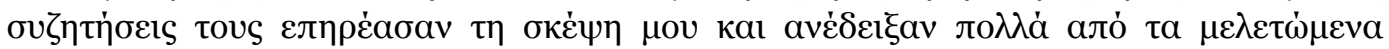

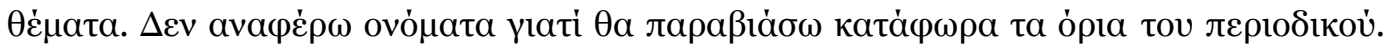

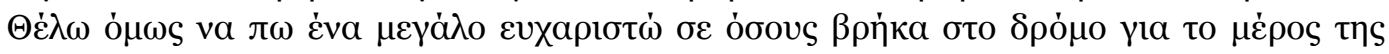

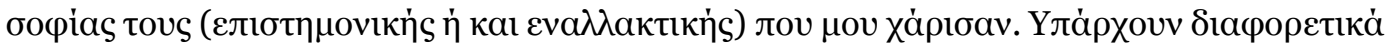

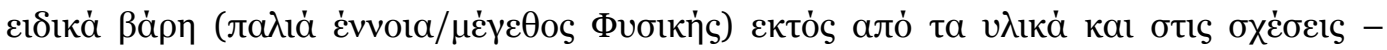

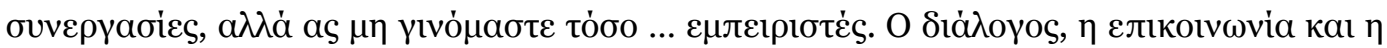

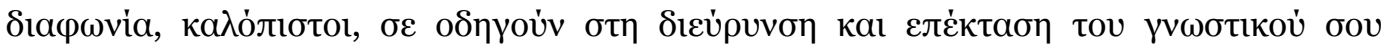

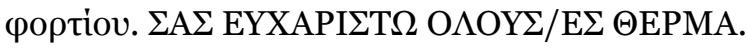

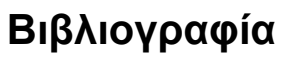

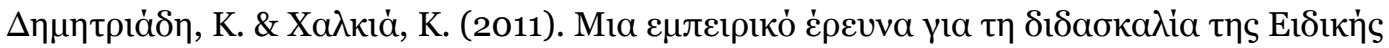

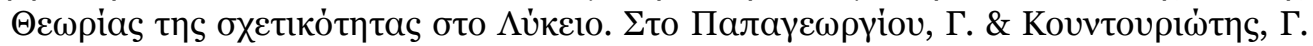

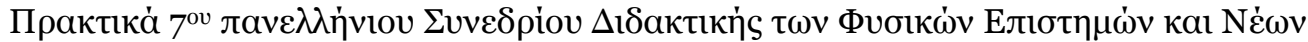

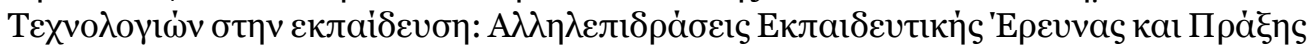

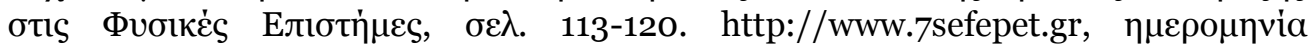

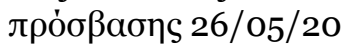

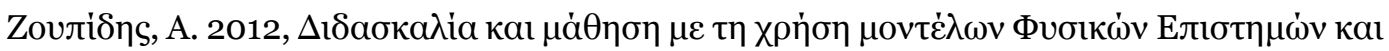

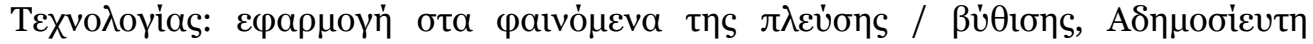

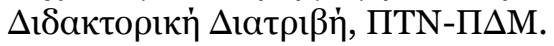

IEП, http://www.iep.edu.gr/el/?view=article\&id=2141:programmata-spoudon-files2\&catid =2, Аvaкті்

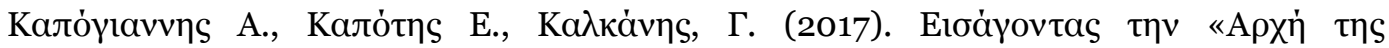

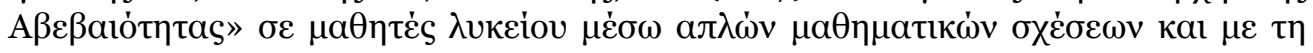

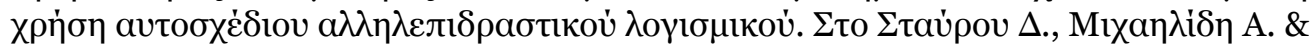

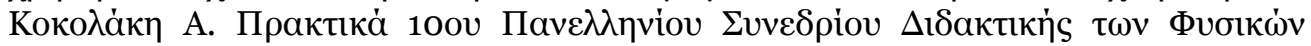

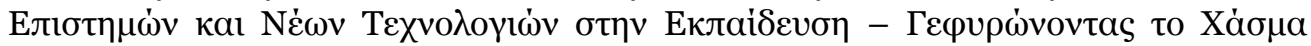

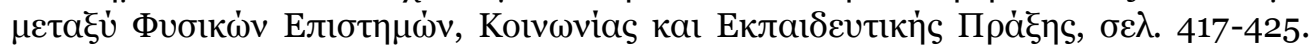

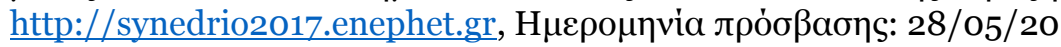

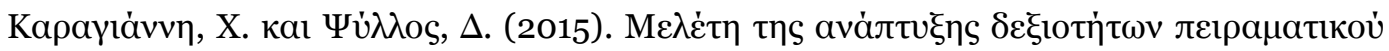

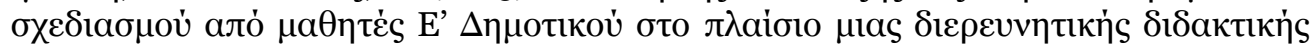

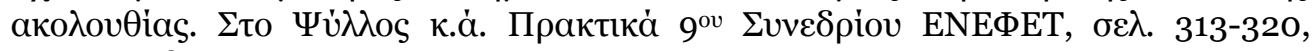
$\Theta \varepsilon \sigma \sigma a \lambda o v i k \eta$.

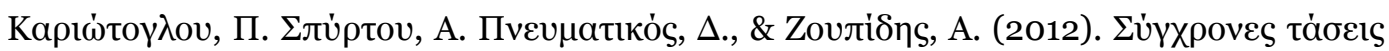

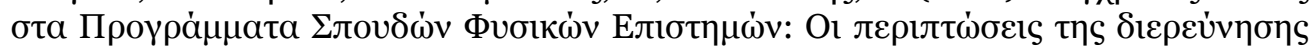

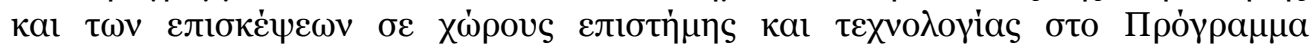




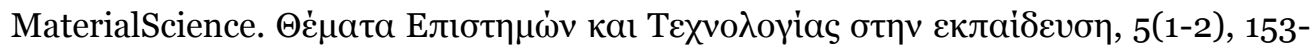
164. http://earthlab.uoi.gr/thete/index.php/thete/article/view/140/90

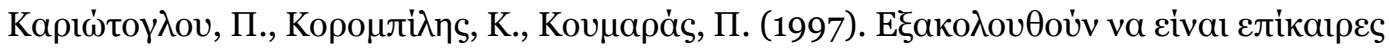

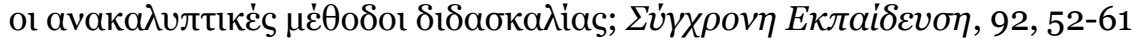

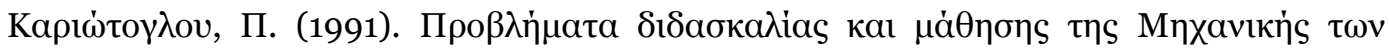

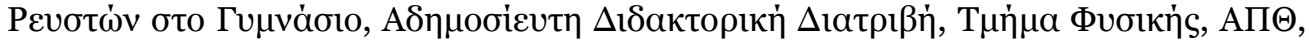
$\sigma \varepsilon \lambda .350$.

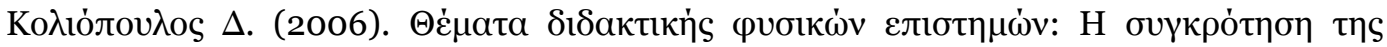

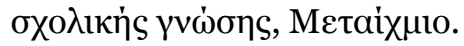

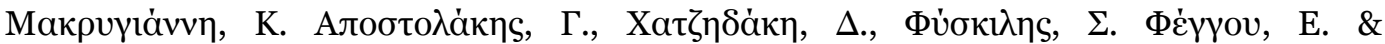

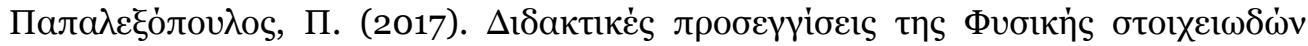

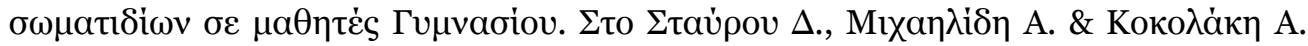

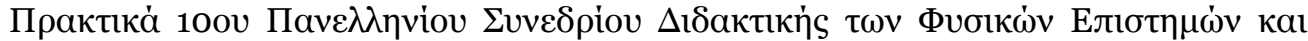

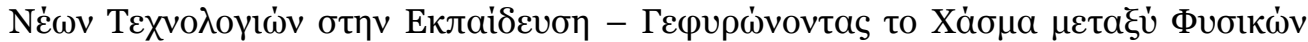

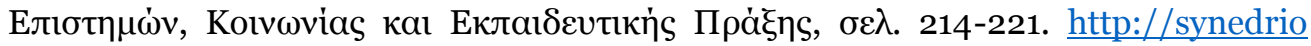

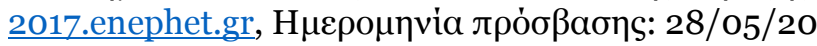

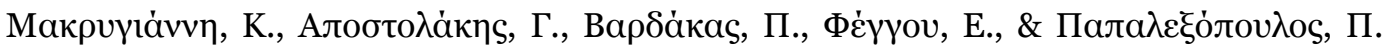

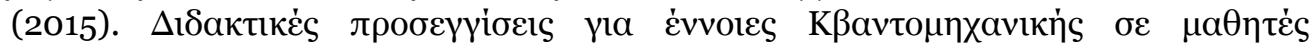

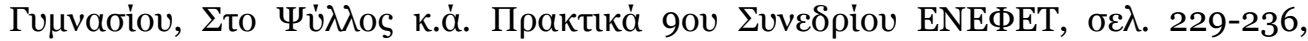
$\Theta \varepsilon \sigma \sigma \alpha \lambda o v i k \eta$.

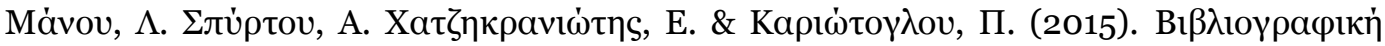

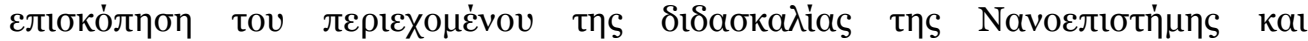

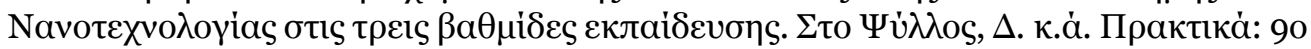

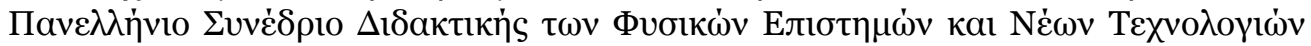

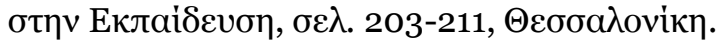

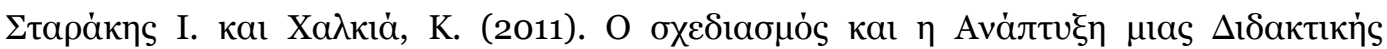

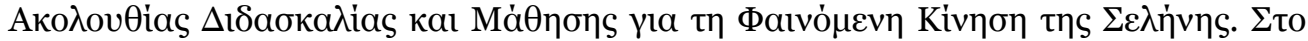

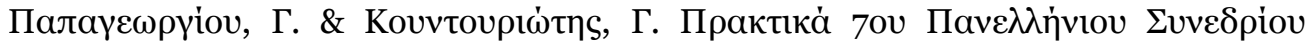

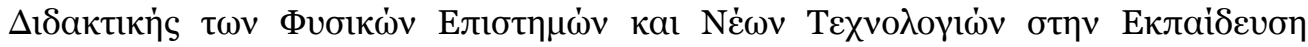

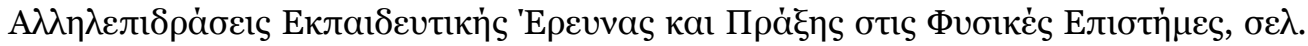

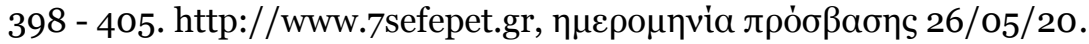

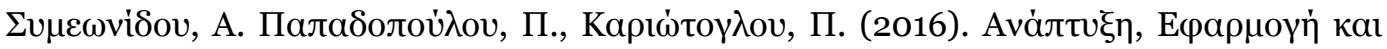

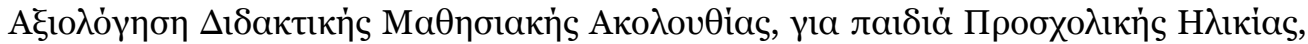

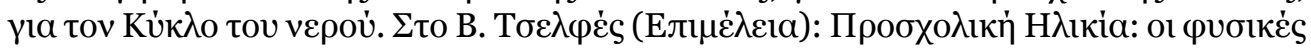

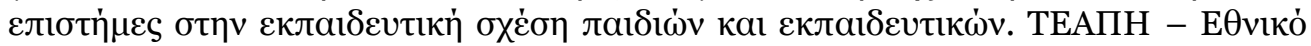

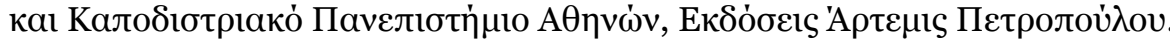

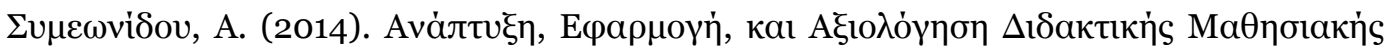

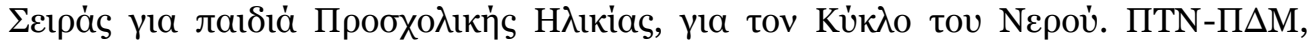

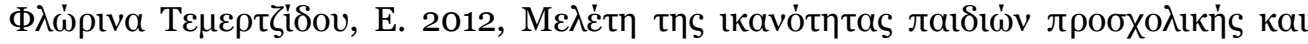

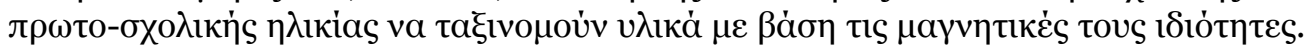

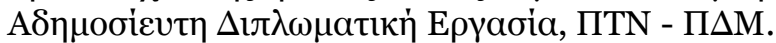




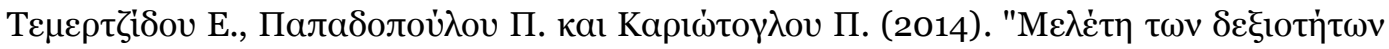

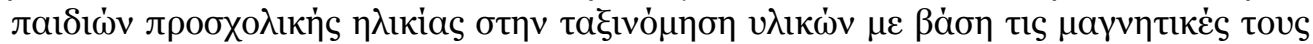

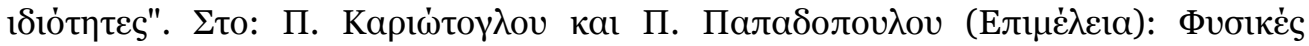

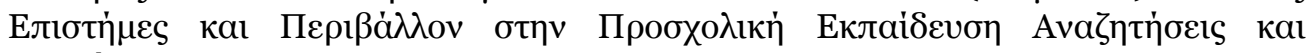

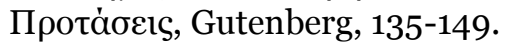

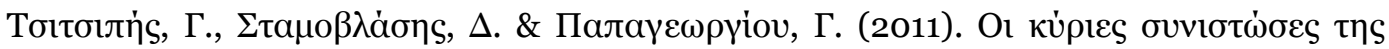

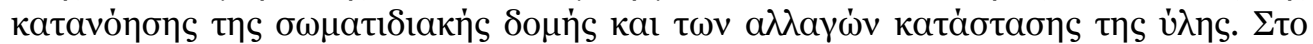

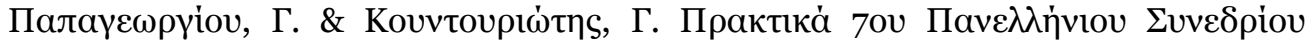

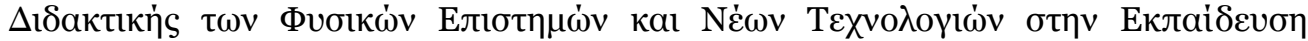

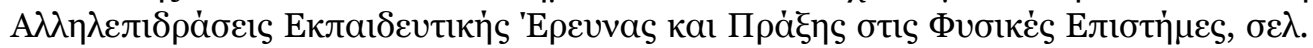

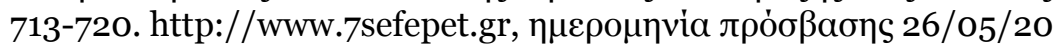

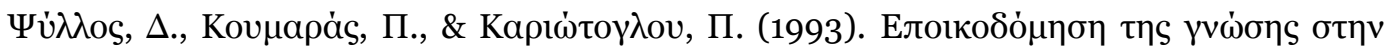

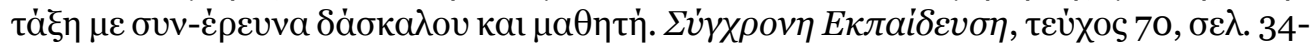
42.

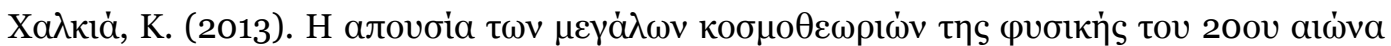

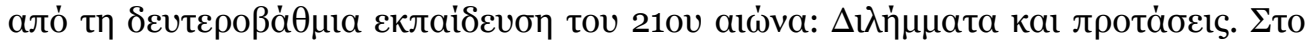

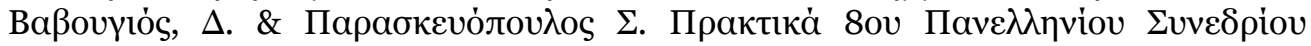

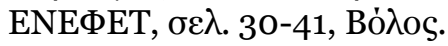

Aikenhead, G.S. (1994). What is STS science teaching? In Solomon, J. \& G. Aikenhead (eds.), STS Education: International Perspectives in Reform. New York: Teacher's College Press.

Bailin, S. (2002) Critical Thinking and Science Education, Science \& Education 11: 361375 .

Bergsten, C., Jablonka, E., \& Klisinska, A. (2010). A remark on didactic transposition theory. In C. Bergsten, E. Jablonka, \& T. Wedege (Red.), Mathematics and mathematics education: Cultural and social dimensions. Proceedings of MADIF 7: The Seventh Swedish Mathematics Education Research Seminar (s. 58-68). Linköping: Svensk Förening för Matematik Didaktisk Forskning.

Borghi, L., De Ambrosis, A., \& Mascheretti, P. (2007). Microscopic models for bridging electrostatics and currents, Physics Education, 42(2), 146-155.

Boudreaux, A., Shaffer, P., Heron, P., \& McDermott, L. (2008). Student understanding of control of variables: Deciding whether or not a variable influences the behavior of a system, American Journal of Physics, vol. 76, no.2, 163-170. doi:10.1119/1.2805235

Chevallard, Y. (1985). La transposition didactique: Du savoir savant au savoir enseigné. Grenoble: La Pensée Sauvage.

Chi, M.T.H., Slotta, J.D. \& De Leeuw, N.D. (1994). From things to processes: a theory of conceptual change for learning science concepts. Learning and Instruction, 4(1), 2743 .

Driver, R., Squires, A., Rushworth, P., \& Wood-Robinson, V. (1994). Making sense of secondary science. London, Routledge. 
Develay. M. (1994). L’apprentissage, l'enseignement et la pédagogie différenciée. Le Nouvel Educateur $\mathrm{n}^{\circ} 56$.

Duit, R., Gropengieber, H., Kattmann, U., Komorek, M., \& Parchmann, I. (2012). The model of educational reconstruction - A framework for improving teaching and learning science. Cultural Perspectives in Science, 5, 13-37.

Duit, R. (2007). Science education research internationally: conceptions, research methods, domains of research. Eurasia Journal of Mathematics, Science and Technology Education, 3(1), 3-15. https://doi.org/10.12973/ejmste/75369

Duit, R., \& Treagust, D. F. (1998). Learning in science-From behaviorism towards social constructivism, beyond. In B. J. Fraser \& K. Tobin (Eds.), International handbook of Science Education, Part 1 (pp. 3-25). Dordrecht, The Netherlands: Kluwer Academic Publishers.

Duschl, R., \& Grandy, R. (2008). Reconsidering the character and role of inquiry in school science: Framing the debates. In R. Duschl \& R. Grandy (eds.), Teaching scientific inquiry: Recommendations for research and implementation (pp. 1-37). The Netherlands, Rotterdam: Sense Publishers.

EU. (2015). Science Education for Responsible Citizenship. Report to the European Commission of the expert group on science education. Luxembourg: Publications Office of the European Union. Doi: 10.2777/13004.

Freudenthal, H. (1986). Book reviews: Yves Chevallard, La Transposition Didactique du Savoir Savant au Savoir Enseigne, Editions Pensie Sauvage, Grenoble, 127 pp. Educational Studies in Mathematics, 17, 323-327.

Kariotoglou, P. \& Zoupidis, A. (2019). Science content transformation: views, criticism, examples and proposal. Oral presentation in the 13th ESERA Conf. Bologna, Italy.

Kariotoglou, P. Papadopoulou, P. Koledinis, N. Strangas, N. (2013). Educating pre-school student teachers to instructional design. In Constantinou, C. P., Papadouris, N. Hadjigeorgiou, A.: Proceedings of the 2013 ESERA Conference, Cyprus.

Kariotoglou, P., Spyrtou, A., \& Tselfes, V. (2008). How student - teachers understand distance force interactions in different contexts, International Journal of Science and Mathematics Education, 7(5), 851-873.

Kariotoglou, P., Koumaras, P. and Psillos, D. (1995). Différentiation conceptuelle: un enseignement d'hydrostatique fondé sur le développement et la contradiction des conceptions des élèves [Conceptual differentiation: a teaching of hydrostatic founded on the development and contradiction of pupils' conceptions]. Didaskalia, 7, 63-90.

Kariotoglou, P., \& Psillos, D. (1993). Pupils' Pressure Models and their implications for instructions, Research in Science and Technological Education, 11, 95-108.

Kariotoglou, P., Koumaras, P., \& Psillos, D. (1993). A constructivist approach for teaching fluid phenomena, Physics Education, 28, 164-169.

Kariotoglou, P., Psillos, D., \& Vallasiades, O. (1990). Understanding pressure: didactical transposition and pupils' conceptions, Physics Education, 25, 92-96. 
Kariotoglou, P., Zoupidis, A., Molochidis, A. (2021). The content didactical transposition/transformation of science in compulsory education: aspects, criticism examples and proposal. It will be submitted for review in an International Journal.

Karplus, R. (1974). SCIS (science curriculum improvement study) Teachers' Handbook, University of California at Berkley, Laurence Hall of Science.

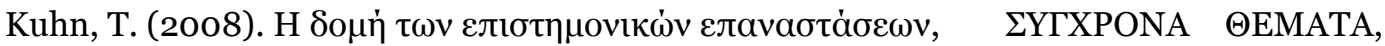

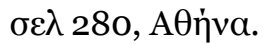

Martinand, J. L. (1989). 'Pratiques de Référence, Transposition Didactique et Savoirs Professionnels en Sciences et Techniques', Les Sciences de l'Education 2, 23-29.

Meheut, M. \& Psillos, D. (2004). Teaching-Learning Sequences: aims and tools for science education research. International Journal of Science Education, 26, 515-535. doi: 10.1080/09500690310001614762

Perlman, H., Makropoulos, C. \& Koutsoyiannis, D. (2005). The water cycle, United States

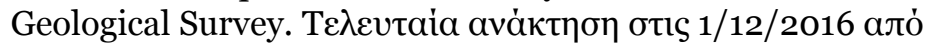

http://ga.water.usgs.gov/edu/watercyclegreek.html

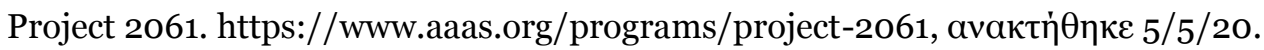

Psillos, D. \& Kariotoglou, P. (Eds) (2016). Iterative design of Teaching-Learning Sequences: Introducing the Science of Materials in European Schools. Springer (collective volume). ISBN 978-94-007-7808-5, p.319.

Psillos, D., Molohidis A., Kallery M., Hatzikraniotis E. (2016). The iterative evolution of a Teaching-Learning Sequence on the Thermal Conductivity of materials in D. Psillos, P. Kariotoglou (eds), "Iterative Design of Teaching - Learning Sequences”, Springer, pp 287-329. ISBN 978-94-007-7807-8.

Psillos and Kariotoglou (1999). Teaching Fluids: Intended knowledge and students' actual conceptual evolution, International Journal of Science Education, Special Issue: "Conceptual Development" (invited), Vol. 21, 17-38.

Schuster, D., Cobern, W.W., Adams, B.A.J., Undreiu, A., Pleasants, B. (2018). Learning of Core Disciplinary Ideas: Efficacy Comparison of Two Contrasting Modes of Science Instruction. Research in Science Education, 48, 389-435 https://doi.org/10.1007/s11165-016-9573-3

Smith, C., Snir, J., \& Grosslight, L. (1992). Using Conceptual Models to Facilitate Conceptual Change: The Case of Weight-Density Differentiation, Cognition and Instruction, 9(3), 221-283. doi:10.1207/s1532690xcio903_3

Spyrtou, A., Hatzikraniotis, E., \& Kariotoglou, P. (2009) Educational software for improving learning aspects of Newton's Third Law for student-teachers, Educational and Informational Technologies, 14(2), 163-187.

Spyrtou, A., Zoupidis, A., Kariotoglou, P. (2008). The design and development of an ICTEnhanced Module concerning density as a property of materials applied in floatingsinking phenomena. In: C. P. Constantinou \& N. Papadouris (Eds.), GIREP International Conference, Physics Curriculum Design, Development and Validation, Selected Papers, pp. 391-407. ISBN 978-9963-689-20-0. 
http://lsg.ucy.ac.cy/girep2008/papers/THE\%20DESIGN\%20AND\%20DEVELOPM ENT\%20OF\%20AN\%20ICT-ENHANCED.pdf

Strauss, A., \& Corbin, J. (1998). Basics of qualitative research: Techniques and procedures for developing grounded theory. Thousand Oaks, CA: Sage.

Vosniadou, S. (Ed) (2013). International Handbook of Research on Conceptual Change, Rutledge, London.

Zoupidis, A., Pnevmatikos D., Spyrtou, A., and Kariotoglou, P. (2016). The impact of the acquisition of Control of Variables Strategy and nature of models in floating-sinking phenomena reasoning and understanding of density as property of materials, Instructional Science. 


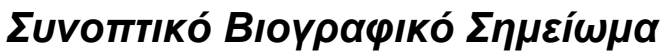

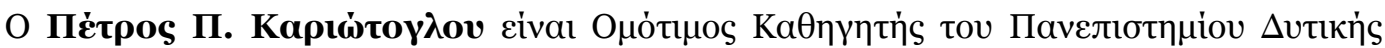

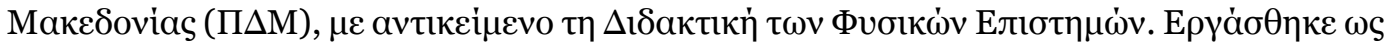

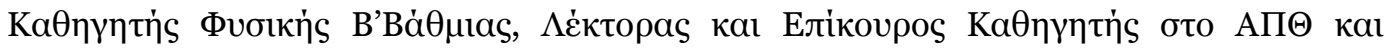

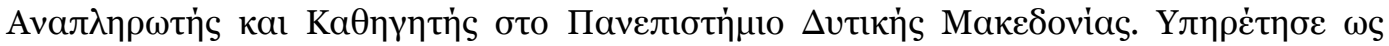

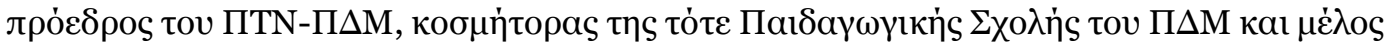

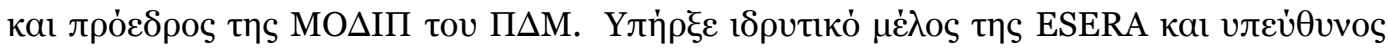

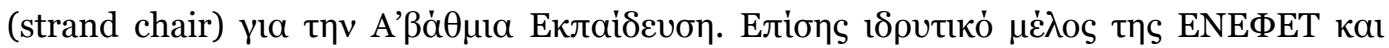

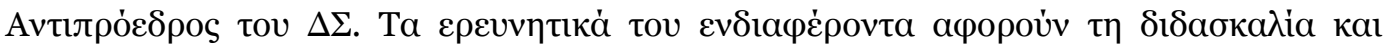

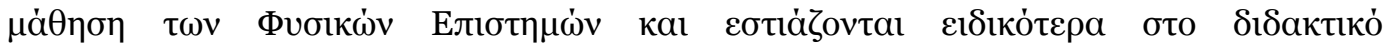

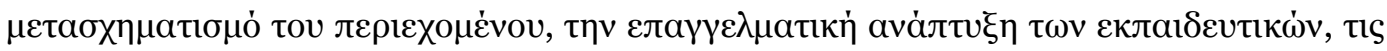

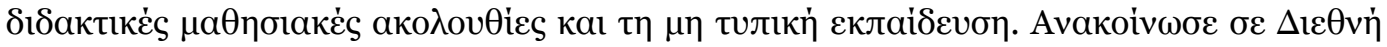

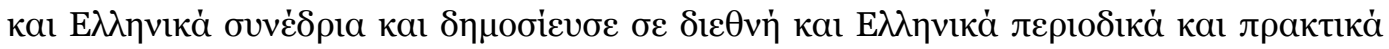

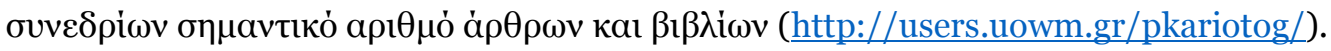

